\title{
Examining the predictability of the Stratospheric Sudden Warming of January 2013 using multiple NWP systems
}

Article

Published Version

Tripathi, O. P., Baldwin, M., Charlton-Perez, A., Charron, M., Cheung, J. C. H., Eckermann, S. D., Gerber, E., Jackson, D. R., Kuroda, Y., Lang, A., Mclay, J., Mizuta, R., Reynolds, C., Roff, G., Sigmond, M., Son, S.-W. and Stockdale, T. (2016) Examining the predictability of the Stratospheric Sudden Warming of January 2013 using multiple NWP systems. Monthly Weather Review, 144 (5). pp. 1935-1960. ISSN 00270644 doi: https://doi.org/10.1175/MWR-D-15-0010.1 Available at https://centaur.reading.ac.uk/56573/

It is advisable to refer to the publisher's version if you intend to cite from the work. See Guidance on citing.

Published version at: http://dx.doi.org/10.1175/MWR-D-15-0010.1

To link to this article DOI: http://dx.doi.org/10.1175/MWR-D-15-0010.1

Publisher: American Meteorological Society

All outputs in CentAUR are protected by Intellectual Property Rights law, including copyright law. Copyright and IPR is retained by the creators or other copyright holders. Terms and conditions for use of this material are defined in the End User Agreement. 


\section{www.reading.ac.uk/centaur}

\section{CentAUR}

Central Archive at the University of Reading

Reading's research outputs online 


\title{
${ }^{\partial}$ Examining the Predictability of the Stratospheric Sudden Warming of January 2013 Using Multiple NWP Systems
}

\author{
OM P. Tripathi, ${ }^{\mathrm{a}}$ Mark Baldwin, ${ }^{\mathrm{b}}$ Andrew Charlton-Perez, ${ }^{\mathrm{a}}$ Martin Charron, ${ }^{\mathrm{c}}$ \\ JACOB C. H. Cheung, ${ }^{\mathrm{d}}$ STEPHEN D. ECKERMANN, ${ }^{\mathrm{e}}$ EDWIN Gerber, ${ }^{\mathrm{f}}$ DAVID R. JACKSON, ${ }^{\mathrm{d}}$

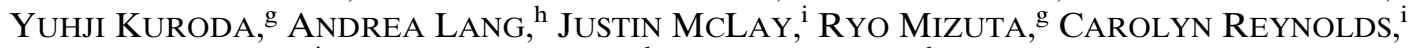 \\ Greg RofF, ${ }^{\mathrm{j}}$ Michael Sigmond, ${ }^{\mathrm{k}}$ SeOK-WoO Son, ${ }^{1}$ AND Tim STOCKDALE ${ }^{\mathrm{m}}$

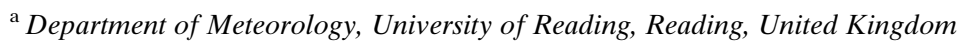 \\ ${ }^{\mathrm{b}}$ College of Engineering, Mathematics and Physical Sciences, University of Exeter, Exeter, United Kingdom \\ ${ }^{\mathrm{c}}$ Meteorological Research Division, Environment Canada, Dorval, Quebec, Canada \\ ${ }^{\mathrm{d}}$ Met Office, Exeter, United Kingdom \\ ${ }^{\mathrm{e}}$ Naval Research Laboratory, Washington, D.C. \\ ${ }^{\mathrm{f}}$ Courant Institute of Mathematical Sciences, New York University, New York, New York \\ ${ }^{\mathrm{g}}$ Meteorological Research Institute, Tsukuba, Japan \\ ${ }^{\mathrm{h}}$ Atmospheric and Environmental Sciences, University at Albany, State University of New York, \\ Albany, New York

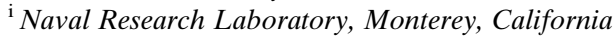 \\ ${ }^{\mathrm{j}}$ Centre for Australian Weather and Climate Research, Bureau of Meteorology, Melbourne, Australia \\ ${ }^{\mathrm{k}}$ Canadian Centre for Climate Modelling and Analysis, Environment Canada, Victoria, \\ British Columbia, Canada \\ ${ }^{1}$ School of Earth and Environmental Sciences, Seoul National University, Seoul, South Korea \\ ${ }^{\mathrm{m}}$ European Centre for Medium-Range Weather Forecasts, Reading, United Kingdom
}

(Manuscript received 11 January 2015, in final form 5 November 2015)

\begin{abstract}
The first multimodel study to estimate the predictability of a boreal sudden stratospheric warming (SSW) is performed using five NWP systems. During the 2012/13 boreal winter, anomalous upward propagating planetary wave activity was observed toward the end of December, which was followed by a rapid deceleration of the westerly circulation around 2 January 2013, and on 7 January 2013 the zonal-mean zonal wind at $60^{\circ} \mathrm{N}$ and $10 \mathrm{hPa}$ reversed to easterly. This stratospheric dynamical activity was followed by an equatorward shift of the tropospheric jet stream and by a high pressure anomaly over the North Atlantic, which resulted in severe cold conditions in the United Kingdom and northern Europe. In most of the five models, the SSW event was predicted 10 days in advance. However, only some ensemble members in most of the models predicted weakening of westerly wind when the models were initialized 15 days in advance of the SSW. Further dynamical analysis of the SSW shows that this event was characterized by the anomalous planetary wavenumber-1 amplification followed by the anomalous wavenumber- 2 amplification in the stratosphere, which resulted in a split vortex occurring between 6 and 8 January 2013. The models have some success in reproducing wavenumber-1 activity when initialized 15 days in advance, but they generally failed to produce the wavenumber-2 activity during the final days of the event. Detailed analysis shows that models have reasonably good skill in forecasting tropospheric blocking features that stimulate wavenumber-2 amplification in the troposphere, but they have limited skill in reproducing wavenumber- 2 amplification in the stratosphere.
\end{abstract}

๑ Denotes Open Access content.

Corresponding author address: Om P. Tripathi, Department of Meteorology, University of Reading, Earley Gate, Reading RG66BB, United Kingdom.

E-mail: o.p.tripathi@reading.ac.uk

\section{Introduction}

A sudden stratospheric warming (SSW) event is characterized by a rapid deceleration in stratospheric circumpolar westerly winds. In the case of a major SSW, the deceleration results in easterly flow in the upper and midstratosphere and in a large increase in the temperature 
(up to $\sim 50 \mathrm{~K}$ ) (e.g., Limpasuvan et al. 2004) of the polar cap region on the time scale of a few days. SSWs are ubiquitous features of the Northern Hemisphere wintertime stratospheric circulation, while in the Southern Hemisphere midwinter SSWs are not common and have only been observed once, in the year 2002. It was not until radiosondes began to provide routine observations of stratospheric levels that the first SSW was documented (Scherhag 1952). Since then, SSWs have been studied extensively both theoretically as well as from the observations. It is now well established that SSWs are caused by the breaking of planetary waves, which propagate from the troposphere into the stratosphere. A major SSW is defined to occur when the zonal-mean zonal wind at or near $10 \mathrm{hPa}$ and $60^{\circ} \mathrm{N}$ reverses direction from westerly to easterly (Andrews et al. 1987; Charlton and Polvani 2007).

SSW events may be classified into vortex-displacement and vortex-splitting types. Vortex-displacement-type SSWs are caused by the anomalous amplification of wavenumber1 (wave-1) planetary waves. These waves upon entering into the stratosphere cause the vortex to be displaced away from the pole. Vortex-splitting-type SSWs are caused either by the anomalous amplification of wavenumber-2 (wave-2) planetary waves or by the sequential anomalous amplifications of wave- 1 followed by wave- 2 . A comprehensive analysis of displacement and splitting types of SSWs, seen in observations, is given by Charlton and Polvani (2007). Charlton and Polvani show that vortex-splitting SSWs occur mainly in January-February whereas vortex-displacement SSWs can occur at any time during the winter.

SSWs have been shown to have a significant impact on the tropospheric circulation. Following an SSW, there can be an equatorward shift of the tropospheric jet with associated anomalously cold conditions in the Northern Hemisphere winter over northern Europe and anomalously warm conditions over northeastern Canada and Greenland. These anomalous conditions are accompanied by changes in precipitation and sea level pressure (Baldwin and Dunkerton 1999, 2001; Thompson et al. 2002), which means that the ability of an NWP system to predict SSW events can contribute to the model's overall tropospheric forecast skill. The idea that enhancing the representation of the stratosphere in NWP models might add to models' skill on shortto medium-range time scales was first expressed by Boville and Baumhefner (1990), and has been confirmed by many recent studies (e.g., Charlton et al. 2004; Jung and Barkmeijer 2006; Kuroda 2010; Roff et al. 2011). However, Sigmond et al. (2013) showed that the enhanced tropospheric skill for the time scale of 16-60 days-associated with improved stratospheric fidelity in NWP models-is conditional. They found that such enhanced tropospheric skills are associated with only those forecasts that are initialized at or close to the onset of SSW events.
Efforts to predict SSWs in operational forecasting systems began in the 1980s. Using a series of 10-day forecasts from a general circulation model, Mechoso et al. $(1985,1986)$ attempted to predict the SSW that occurred in the 1979/80 Northern Hemisphere winter. Their results suggested that the SSW was predictable about 5 days in advance. Since the pioneering work of Mechoso et al., there have been several other studies on SSW predictability. A surge in SSW predictability studies followed the works of Baldwin and Dunkerton (1999, 2001), which showed that stratospheric variability impacts tropospheric circulation (e.g., Simmons et al. 2003; Mukougawa and Hirooka 2004; Simmons et al. 2005; Mukougawa et al. 2005; Allen et al. 2006; Jung and Leutbecher 2007; Hirooka et al. 2007; Stan and Straus 2009; Marshall and Scaife 2010).

Recently, Tripathi et al. (2015) reviewed published literature on SSW predictability, which highlighted both the studies that have attempted to quantify the predictability in different NWP systems as well as the studies that have focused on the current understanding of the factors that influence stratospheric predictability. In a single model, the lead time at which an SSW can be successfully predicted can vary from 5 to 14 days. However, it is difficult to intercompare stratospheric predictive skill between models when studies use different experimental methodologies or examine different events [see Table 1 of Tripathi et al. (2015)].

In the present study, we begin to address this problem by performing a coordinated set of forecast experiments of the same SSW with five different operational NWP systems. These experiments form the first phase of a Stratosphere-Troposphere Processes and their Role in Climate (SPARC) initiative: the Stratospheric Network for the Assessment of Predictability (SNAP) ${ }^{1}$ which is in the process of compiling a detailed dataset of NWP systems open for use by the community.

The main scientific objectives of this paper are to answer the following questions:

1) How predictable was the SSW event?

2) How does its predictability differ between the models and/or ensemble members?

3) What limits the predictability of the SSW?

We, however, make it clear that the results of this multimodel study are based on only one case. We are hopeful that the findings will generalize to other such cases and possibly intensify the effort to plan more such experiments.

\footnotetext{
${ }^{1}$ For more details please visit the SNAP homepage at http:// www.sparcsnap.org/.
} 
The paper is organized as follows. In the next section, the NWP models and the data for verification are briefly described. In section 3, we present detailed experimental specifications and the diagnostics we employ. Section 4 examines the predictability of the event and will show the differences between the models and the differences among the ensemble members. In section 5, we use more diagnostics to understand what limits the predictability in the models and in the ensemble members. In section 6 , we present our conclusions.

\section{Models and data}

The dataset used in this study is made up of a collection of ensemble forecast model runs from the operational forecasting centers listed in Table 1 . The model results are compared to 6-hourly fields $(0000,0600,1200$, and 1800 UTC) from the European Centre for MediumRange Weather Forecasts (ECMWF) interim reanalysis (ERA-Interim). Table 1 provides the specifications for each model. A detailed description of each model's setup is provided in the following section.

\section{a. CAWCR AGREPS}

The Centre for Australian Weather and Climate Research (CAWCR) is located within the Environment and Research Division of the Australian Bureau of Meteorology (BoM) and, under the Australian Community Climate and Earth-System Simulator (ACCESS) framework, has been running the ACCESS Global and Regional short range Ensemble Prediction System (AGREPS) in preoperational research mode for the past few years.

The current AGREPS, which produces 10-day forecasts, uses the Met Office finite-difference nonhydrostatic dynamical core (Unified Model, version 7.9, PS25) on an Arakawa C grid (Arakawa and Lamb 1977) in the horizontal, and a Charney-Phillips scheme in the vertical (Charney and Phillips 1953) with a transformed geometricheight coordinate. The horizontal grid has $325 \times 432$ (N216) regular latitude and longitude grid points with grid spacing of $0.555^{\circ}$ and $0.833^{\circ}$, respectively $(\sim 60 \mathrm{~km}$ horizontal grid spacing). The model has 70 vertical levels toping at $\sim 80 \mathrm{~km}(0.009 \mathrm{hPa})$. The prognostic equations are advanced in time using a two time-level, semi-implicit, semi-Lagrangian scheme.

The model parameterizations, as used in the Bureau's National Meteorological and Oceanographic Centre (NMOC) ACCESS Australian Parallel Suite 1 (APS1) Global NWP model (Fraser 2012), are as follows: the convection scheme is a modified mass flux scheme based on Gregory and Rowntree (1990), the radiation scheme was developed by Edwards and Slingo (1996), the Wilson and Ballard (1999) single-moment bulk microphysics scheme is used for precipitation, the prognostic cloud and condensate (PC2) scheme of Wilson et al. (2008) is used, the subgrid boundary layer fluxes are by Lock et al. (2000) and Louis (1979), the land surface interaction is via the Met Office Surface Exchange Scheme (MOSES) II (Essery et al. 2001), and the gravity wave drag scheme includes an orographic gravity wave scheme (Webster et al. 2003) and a spectral gravity wave scheme (Warner and McIntyre 2001).

The current 24-member AGREPS is initialized from the Australian Bureau of Meteorology operational analyses whose observational data assimilation procedure uses a four-dimensional variational data assimilation (4DVAR) scheme. The ensemble initial condition perturbations are generated by the ensemble transform Kalman filter, updated on 12-h cycles, and features a range of model perturbations. Principal among these is the so-called stochastic kinetic energy backscatter scheme, designed to simulate upscale propagating errors due to unresolved subgrid-scale processes, by the application of streamfunction forcing to the momentum equation (Berner et al. 2009). The sea surface temperature and sea ice boundary conditions are persisted throughout the forecast, and they are the same for all ensemble members. In the rest of the article, this model will be referred to as CAWCR.

\section{b. MRI-AGCM}

In the ensemble forecast experiments by the Meteorological Research Institute (MRI), ensemble perturbations are obtained from the MRI Ensemble Prediction System (MRI-EPS) (Yabu et al. 2014), which is constructed by expanding the ensemble forecasting system developed for the operational 1-month forecast in the Japan Meteorological Agency (JMA). The perturbations are made with a breeding of growing mode (BGM) methodology. Initial data for the forecast experiments are made by adding them to the ERA-Interim data.

The forecast experiments are performed using a lowresolution version of the MRI Atmospheric General Circulation Model, version 3.2 (MRI-AGCM3.2) (Mizuta et al. 2012). The grid spacing of the model is set to be the same as the model used to calculate BGM perturbations, which is TL159 (a grid interval of roughly $110 \mathrm{~km}$ ) in the horizontal and 60 levels (top at $0.1 \mathrm{hPa}$ ) in the vertical. This model is based on the previous version of the JMA operational system (Japan Meteorological Agency 2007). While a new cumulus parameterization scheme (Yoshimura et al. 2015) and a cloud scheme based on Tiedtke (1993) are incorporated in the model, the fundamental components of the model are shared with the JMA model, including the dynamical framework, the radiation scheme, the orographic gravity wave drag scheme (Iwasaki et al. 1989), and the planetary boundary layer scheme. Table 1 shows the model's 


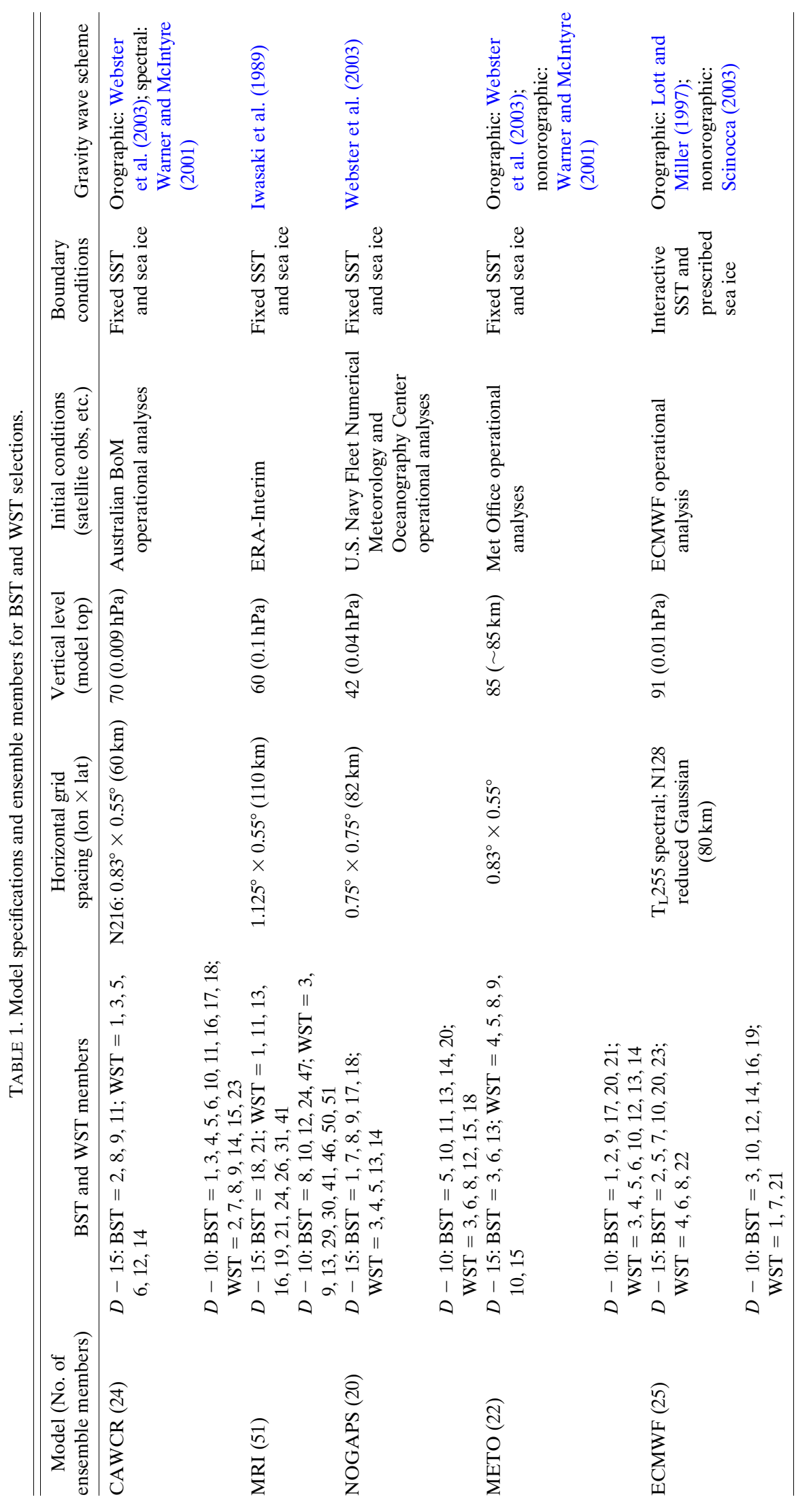


specifications, and for the rest of the paper this model will be referred to as MRI.

\section{c. NOGAPS}

The Navy Operational Global Atmospheric Prediction System (NOGAPS) is a global model with a spectral representation in the horizontal plane and a finite-difference approximation in the hybrid sigma/ pressure vertical coordinate. A semi-implicit scheme is used for the time integration. The subgrid physical parameterizations include the surface-flux scheme of Louis (1979), and a vertical diffusion scheme is based upon a $K$-theory approximation (Louis et al. 1982). Shallow convection is parameterized as in Tiedtke (1984), and deep convection is treated using the scheme of Emanuel (1991) (see also Emanuel and Zivkovic-Rothman 1999). The radiation scheme is that of Harshvardhan et al. (1987). Clouds from deep convection are parameterized using the scheme of Slingo (1987), and boundary layer clouds are treated following Teixeira and Hogan (2002) and Teixeira (2001). Gravity wave drag is represented following Webster et al. (2003). For the ensemble forecasts, the horizontal grid spacing is approximately $82 \mathrm{~km}$ (T159).

Initial conditions for the NOGAPS forecast ensemble are generated using a nine-banded local ensemble transform (ET) scheme (McLay et al. 2010). In this methodology, short-term ensemble forecasts are linearly combined, under the constraint of an estimate of the analysis error variance, to produce a set of perturbations to the analysis from the Naval Research Laboratory Atmospheric Variational Data Assimilation System-Accelerated Representer (NAVDAS-AR) (Rosmond and Xu 2006; Chua et al. 2009). The ensembles consist of 20 members and are run out to 15 days. The SST analysis valid at initial time is held fixed through the forecast integration. The term NOGAPS will be used for this model.

\section{d. Met Office Unified Model}

The Met Office Unified Model is a global model with a dynamical core that uses a semi-implicit, semiLagrangian formulation to solve the nonhydrostatic, fully compressive deep-atmosphere equations of motion (Davies et al. 2005). It includes a comprehensive set of state-of-the-art parameterizations [see Walters et al. (2014) for details], including a parameterization of nonorographic gravity waves using the ultra-simple spectral parameterization [see Warner and McIntyre (2001) and references therein]. The ensemble forecasts used here consist of 22 members. The forecasts are run at a horizontal grid spacing of $\mathrm{N} 216\left(0.83^{\circ}\right.$ longitude by $0.55^{\circ}$ latitude) and on 85 vertical levels that extend from the surface to $85 \mathrm{~km}$ in altitude. The forecasts are initialized from Met Office operational analyses, and the ensemble perturbations are calculated using the Met Office Global and Regional Ensemble Prediction System (MOGREPS) (Bowler et al. 2008). We will use the term METO for this model.

\section{e. ECMWF System 4}

The ECMWF has several operational forecast systems covering different time scales. The most natural to use in this study is the ensemble prediction system (ENS) configuration, which produces 51-member ensemble forecasts out to 15 days twice every day. However, for the dates in this study the ENS was running as a low-top model, with the highest level at $5 \mathrm{hPa}$ and had very poor resolution in the midstratosphere. It was thus decided to use the long-range forecasting System 4, operational since November 2011, which uses 91 levels and includes the full stratosphere. The ENS configuration has since been upgraded to use the same vertical grid spacing as used in this study. System 4 is based on the Integrated Forecast System (IFS), running at $\mathrm{T}_{\mathrm{L}} 255 \mathrm{~L} 91$, coupled to a global $1^{\circ}$ grid spacing configuration of the Nucleus for European Modelling of the Ocean (NEMO) ocean model (with reduced grid spacing in the tropical oceans). Sea ice is persisted for the first 10 days of the forecast, and is then relaxed toward a specified file sampled separately for each ensemble member from the previous five years. The IFS has a comprehensive treatment of physical processes.

Points to note for this study are the treatment of orographic (Lott and Miller 1997) and nonorographic [an implementation of Scinocca (2003)] gravity wave drag and the two-time level semi-Lagrangian numerics. Initial conditions for the ocean come from Ocean Reanalysis System 4 (ORAS4) (Balmaseda et al. 2013), and for the atmosphere the initial conditions come from the operational analysis rather than ERA-Interim. Further details of System 4 are available in Molteni et al. (2011). The term ECMWF will be used for this model in the remainder of the article.

\section{Experimental specifications and diagnostics}

Each of the operational models was run to create a dataset of ensemble forecasts for the SSW that occurred on 7 January 2013. Initial dates for the forecasts were chosen with reference to the SSW central date (7 January 2013) when winds at $60^{\circ} \mathrm{N}$ and $10 \mathrm{hPa}$ reversed, as represented in the ERA-Interim dataset. Each of the models was run five times, with each run corresponding to a different initialization date. These initialization dates correspond to 23 December 2012, 15 days prior to the SSW ( $D-15)$; 28 December 2012, 10 days prior to 
(a)
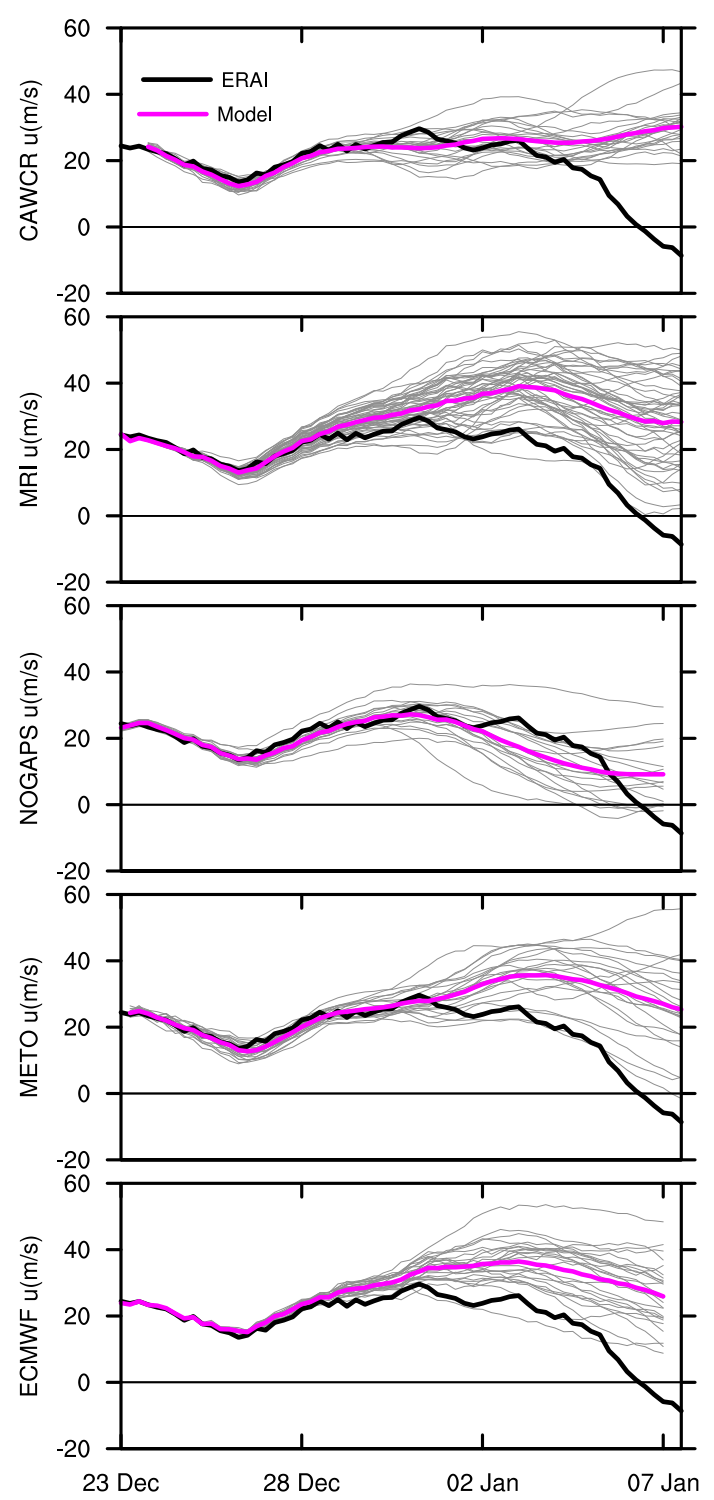

D-10
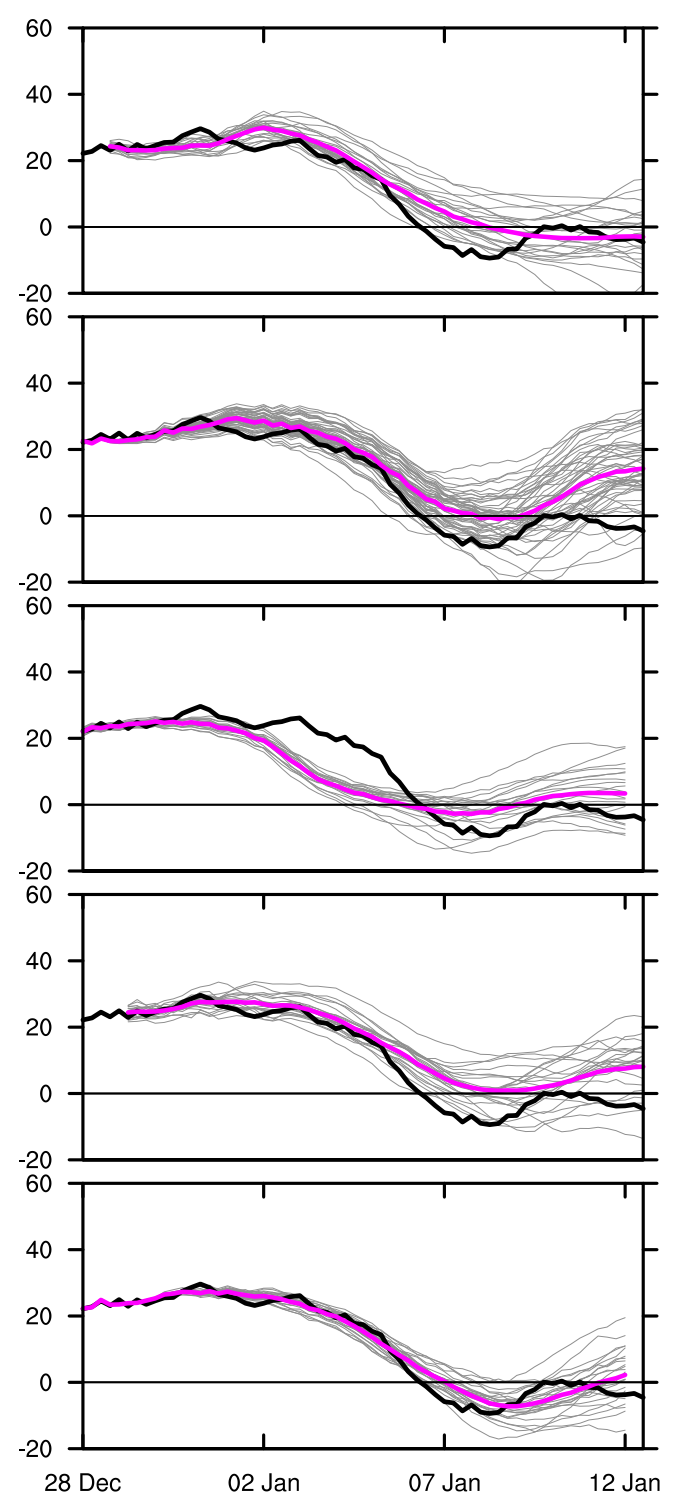

FIG. 1. (a) Zonal-mean zonal wind at $10 \mathrm{hPa}$ and $60^{\circ} \mathrm{N}$ from ERA-Interim (thick black lines) and model ensemble members (thin gray lines). The thick colored line denotes the ensemble mean. The initialization dates are (left) 23 Dec $2012(D-15)$ and (right) 28 Dec $2012(D-10)$. Vertical date ticks are drawn at 0000 UTC. (b) As in (a), but for the initialization dates of (left) 2 Jan $2013(D-5)$ and (right) 7 Jan $2013(D-0)$.

the SSW $(D-10) ; 2$ January 2013,5 days prior to the SSW $(D-5)$; 7 January 2013, the day of the SSW $(D-$ $0)$; and 12 January 2013, 5 days after the SSW $(D+5)$.

All the models were initialized at 0000 UTC, except CAWCR, which was initialized at 1200 UTC. The model ensembles were run for a minimum of 15 days (METO runs for 30 days). In addition to the standard diagnostics of model variables, elliptical diagnostics showing the polar vortex structure (Waugh 1997), Eliassen-Palm (EP) flux diagnostics (Andrews et al. 1987) of the large-scale wave field, and regression coefficients of geopotential height and EP flux against zonal-mean zonal wind are calculated for all the models and ERA-Interim.

\section{a. Elliptical diagnostics}

The wintertime stratospheric polar vortex edge is recognized as the location of a steep meridional gradient of quasi-conservative tracers like potential vorticity (PV) and long-lived chemical species (e.g., McIntyre and Palmer 1983, 1984; Leovy et al. 1985). During weak 
(b)

D-5
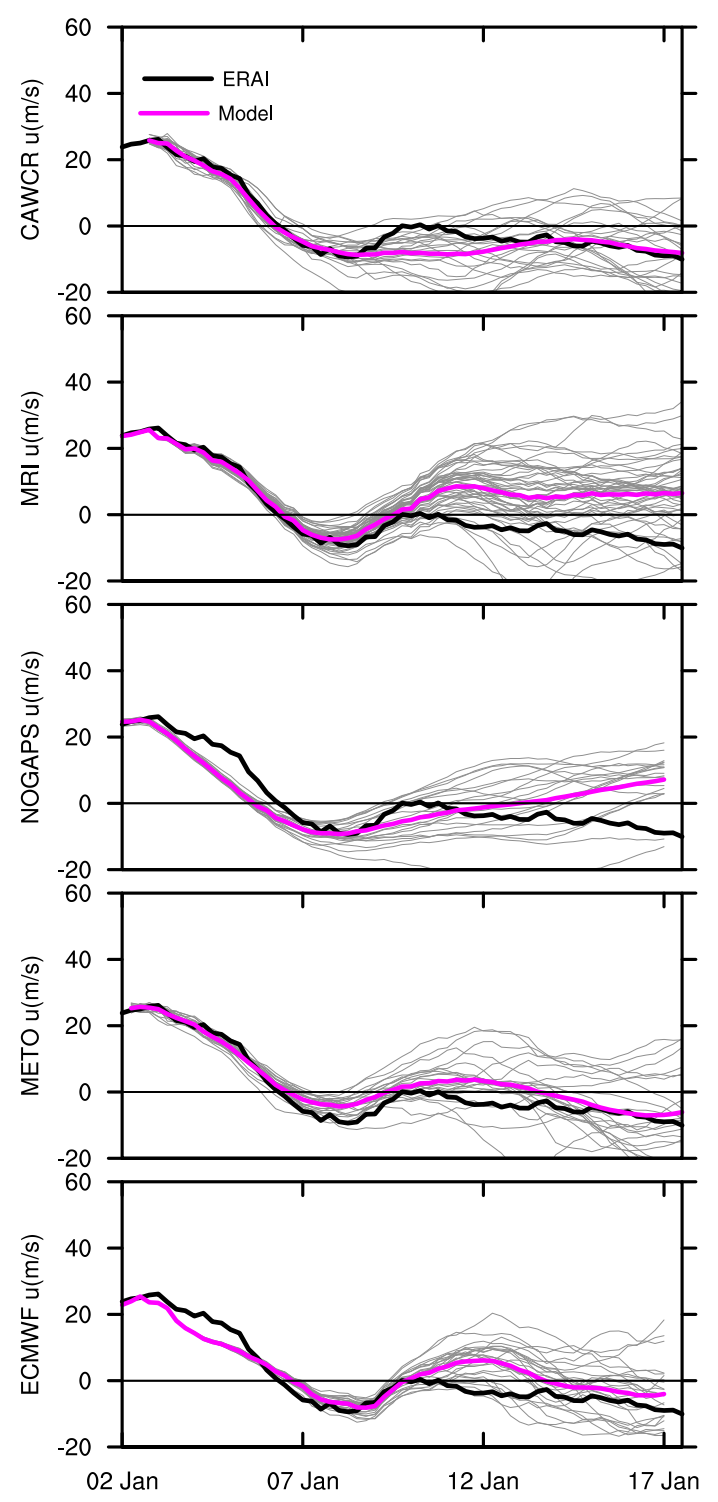

D-0

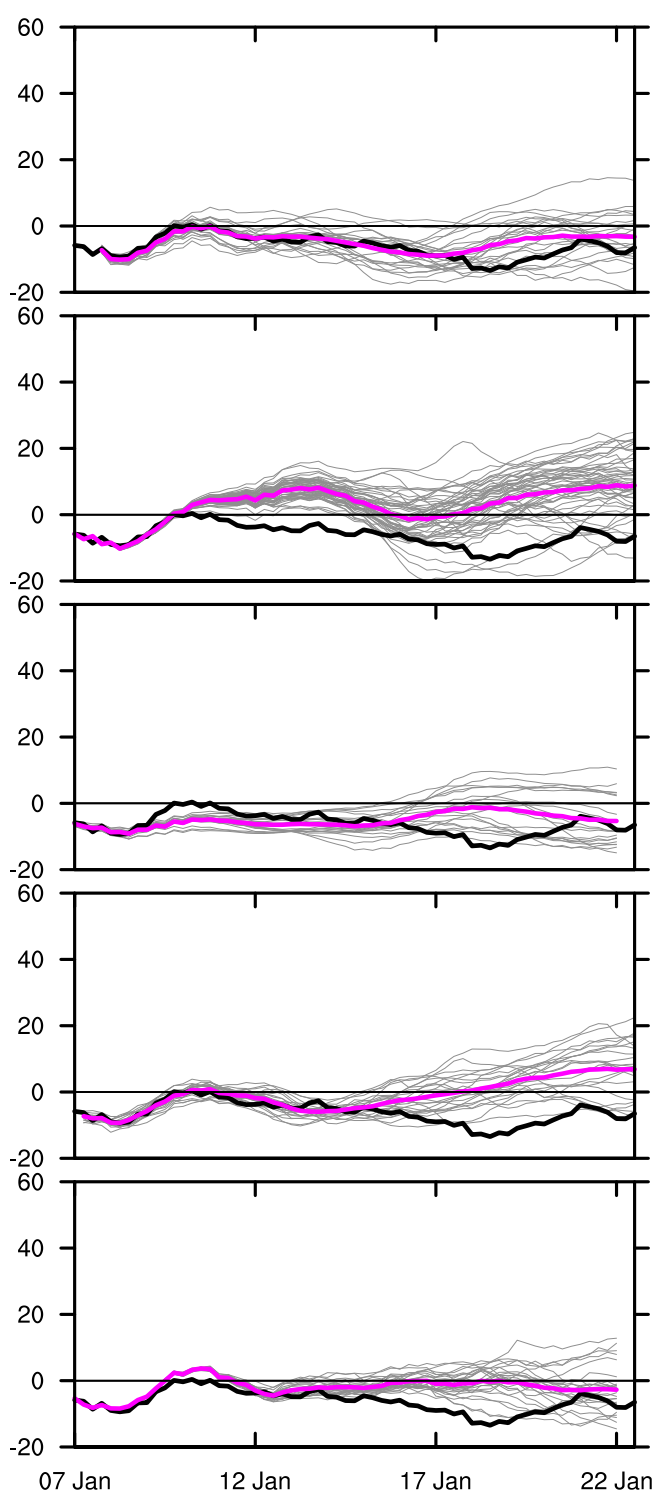

FIG. 1. (Continued)

vortex events such as SSWs, the vortex is highly deformed and vortex air is mixed out of the polar region into the midlatitudes. The mixing usually takes place in the form of long vortex filaments and can be easily visualized using isentropic maps of PV (Leblanc et al. 2006; Tripathi et al. 2006), which show the qualitative structure of the evolution of the vortex during vortex deformation.

A quantitative diagnosis of the structure of the vortex can be obtained from the calculation of a range of "elliptical diagnostics" (e.g., Waugh 1997). The elliptical diagnostics are based on the spatial moments of the PV field, and the diagnostics are used to calculate various geometric parameters of the vortex structure such as the area, the ellipticity, the aspect ratio, and the centroid of the vortex equivalent ellipse. Several previous studies have used elliptical diagnostics to examine stratospheric vortex structure and evolution during deformed stratospheric vortex events (e.g., Waugh 1997; Waugh and Randel 1999; Matthewman et al. 2009; Mitchell et al. 2011). Tracking elliptical diagnostics in time provides information related to the state of the vortex; these diagnostics can be used to track the spatial evolution of the vortex during the deformed vortex events.

The elliptical diagnostics used in this analysis are calculated using the regions north of the equator. The method used to calculate various elliptical diagnostics 
from gridded data, obtained from the operational models and ERA-Interim, is given in the appendix.

\section{b. EP flux diagnostics}

To identify the vertical propagation of wave activity [enhanced angular pseudo-momentum density in the polar stratosphere, see e.g., Andrews and McIntyre $(1976,1978)]$ we use EP flux diagnostics. The EP flux is directly related to $\overline{v^{\prime} T^{\prime}}$. Calculation of the vertical component of the EP flux (Andrews et al. 1987) $\overline{v^{\prime} T^{\prime}}$ is straightforward: $v^{\prime}$ and $T^{\prime}$ are the anomalies from the zonal mean of meridional velocity $v$ and temperature $T$, respectively. The overbar denotes the zonal mean after the $v$ and $T$ anomalies are multiplied at each grid point. The different wave components of $\overline{v^{\prime} T^{\prime}}$ are calculated via Fourier transforms.

\section{c. Regression analysis}

To find phenomena and regions sensitive to the forecast results, a linear regression of ensemble members against the zonal-mean zonal winds at $60^{\circ} \mathrm{N}$ and $10 \mathrm{hPa}$ on $7 \mathrm{Jan}-$ uary 2013 is performed following Mukougawa et al. (2005). We calculated the regression relationship for each model run initialized on 23 December $2012(D-15)$.

\section{Predictability of the event}

In this section, the predictability of the SSW is examined for the different models and initialization times. Figures $1 \mathrm{a}$ and $1 \mathrm{~b}$ show the time series of the zonal-mean zonal wind at $10 \mathrm{hPa}$ and $60^{\circ} \mathrm{N}$ for all ensemble members from different models, initialized at four different dates corresponding to $D-15, D-10, D-5$, and $D-0$. We also calculated hit-rate statistics based on the number of ensemble members meeting the SSW criteria of Charlton and Polvani (2007) within \pm 2 days of the wind reversal in the ERA-Interim dataset (i.e., 7 January 2013). Hit-rate statistics are shown in Table 2.

Figures 1a and $1 \mathrm{~b}$ also show the ensemble mean zonalmean zonal wind and corresponding ERA-Interim values. The ensemble mean of all the models, except NOGAPS, failed to predict the observed substantial weakening and reversal of the zonal winds associated with the SSW when the models were initialized 15 days in advance on 23 December 2012. Only the NOGAPS ensemble mean indicated a substantial weakening of the zonal-mean wind; $25 \%$ of its members (5 out of 20 ) met the SSW criteria (Table 2). A small number of ensemble members of MRI, METO, and ECMWF also showed weakening of the zonal-mean westerlies, but only $2 \%$ ( 1 out of 51 ) and $5 \%$ ( 1 out of 22 ) of the ensemble members of MRI and METO, respectively, were able to meet the SSW criteria in $D-15$ initialization (see the hit rates in Table 2).
When the models were initialized on 28 December $2012(D-10)$, all of the models were able to predict the SSW in the ensemble mean, with comparatively small ensemble spread 10 days after initialization. However, there were differences in different models in the timing of the wind reversal and the percentage of ensemble members meeting the SSW criteria (see, e.g., Table 2). Most successful was ECMWF with $100 \%$ hit rate; the hit rates of all of the models were $50 \%$ or more, giving a strong indication that an SSW was likely to occur. The NOGAPS ensemble mean leads the ERA-Interim wind reversal by about 1 day whereas the CAWCR and METO ensemble means lag behind ERA-Interim by 2 days. In the $D-5$ experiment, all the ensemble members of all the models met the SSW criteria with a $100 \%$ hit rate (Table 2).

CAWCR and ECMWF were not only able to forecast the SSW in the $D-10$ initialization but were also able to sustain the weakened zonal winds after the wind reversal had occurred, suggesting significant predictability even 12 or 13 days after initialization. In contrast, the ensemble mean forecasts of other models predicted a rapid recovery of the zonal-mean zonal winds toward a stronger polar vortex after the SSW. The inability of the models, particularly MRI $(D-5$ and $D-0$ runs), NOGAPS ( $D-5$ run), ECMWF ( $D-5$ run), and METO ( $D-0$ run), to sustain easterly wind after the SSW is also evident from Fig. 1b. The enhanced ensemble spread, for nearly all of the models during the recovery phase of the warming, suggests that the period after the initial westerly deceleration is particularly difficult for the models to predict. Dörnbrack et al. (2012) found a similar increase of ensemble spread for their study of SSW in the 2009/10 winter.

Figure 2 shows the ensemble mean root-mean-square error (RMSE) growth in the models for the $D-15$ and $D-10$ runs, emphasizing the difference in predictability at long lead times for the models in comparison to the one initialized closer to the SSW. One clear difference between the two runs is the increased error growth after about 10 days in the $D-15$ run, particularly in METO, MRI, and ECMWF, which is not as pronounced in the $D-10$ run. CAWCR and NOGAPS show smaller ensemble spread up to about $12-13$ days in the $D-15$ initialization. Similar to the $D-15$ initialization, MRI and METO show a larger error growth after about 12 days in the $D-10$ initialization; the other three models show a smaller error growth up to 15 days in the $D-10$ initialization.

The difference between the ensemble spread in the $D-15$ and $D-10$ initialization underlines the difficulty models encounter when it comes to predicting vortex weakening associated with SSWs with lead 
TABLE 2. Hit-rate statistics: percentage of total ensemble members meeting the criteria of SSW within \pm 2 days of $D-0$ (7 Jan 2013) when the model is initialized on different dates.

\begin{tabular}{lcccc}
\hline \hline & & \multicolumn{3}{c}{$\begin{array}{c}\text { Hit rate (\%) for models } \\
\text { initialized on given date }\end{array}$} \\
\cline { 3 - 5 } Model & $\begin{array}{c}\text { No. of ensemble } \\
\text { members }\end{array}$ & $D-15$ & $D-10$ & $D-5$ \\
\hline CAWCR & 24 & 0 & 71 & 100 \\
MRI & 51 & 2 & 65 & 100 \\
NOGAPS & 20 & 25 & 75 & 100 \\
METO & 22 & 5 & 50 & 100 \\
ECMWF & 25 & 0 & 100 & 100 \\
\hline
\end{tabular}

times longer than 10 days. Some members of NOGAPS, however, predicted the SSW in $D-15$ runs and, as expected, NOGAPS shows the least spread in the $D-15$ case.

The elliptical diagnostics discussed in the previous section are calculated for all model runs and for every time step on the $850-\mathrm{K}$ isentropic surface. Figures $3 \mathrm{a}$ and $3 \mathrm{~b}$ show the vortex evolution using equivalent ellipses to represent the position and structure of the vortex leading to the SSW event. Figures $3 \mathrm{a}$ (top) and $3 \mathrm{~b}$ (top) show the ERA-Interim vortex ellipses, vortex centroids (white plus signs), and mean PV on 30 December 2012, 3 January 2013, and 7 January 2013. The other rows show corresponding ellipses and centroids for all the ensemble members in each of the five models.

Figure 3a (top) shows that on 30 December 2012 the vortex was positioned off the pole, centered above Eurasia. Between 30 December 2012 and 3 January 2013 the vortex became more isotropic, reducing in size slightly, but was centered in the same area. During the following 4 days, the vortex dramatically elongated [shown as the elongation from the lower right to upper left in Fig. 3a (top)] and split into two with the larger piece over northern America and the smaller one over Europe, a typical evolution for vortex-splitting events (Matthewman and Esler 2011).

The period between 4 and 6 January 2013 appears to be critical for the vortex. Comparing the ERA-Interim vortex with $D-15$ model forecasts on 3 January 2013 (Fig. 3a, middle), it is observed that the predicted positions of the vortices in all the models were centered above Europe with the vortex in CAWCR oriented from the upper right to lower left in Fig. 3a. The structure and evolution of the vortex in METO and ECMWF for $D-$ 15 forecasts closely resembles the ERA-Interim vortex (a smaller, circular vortex centered over Europe with least spread among its ensemble members).

By 5 January 2013 (not shown), the vortex in CAWCR for $D-15$ remained centered over the Europe, but there was large variability in the position of centroid
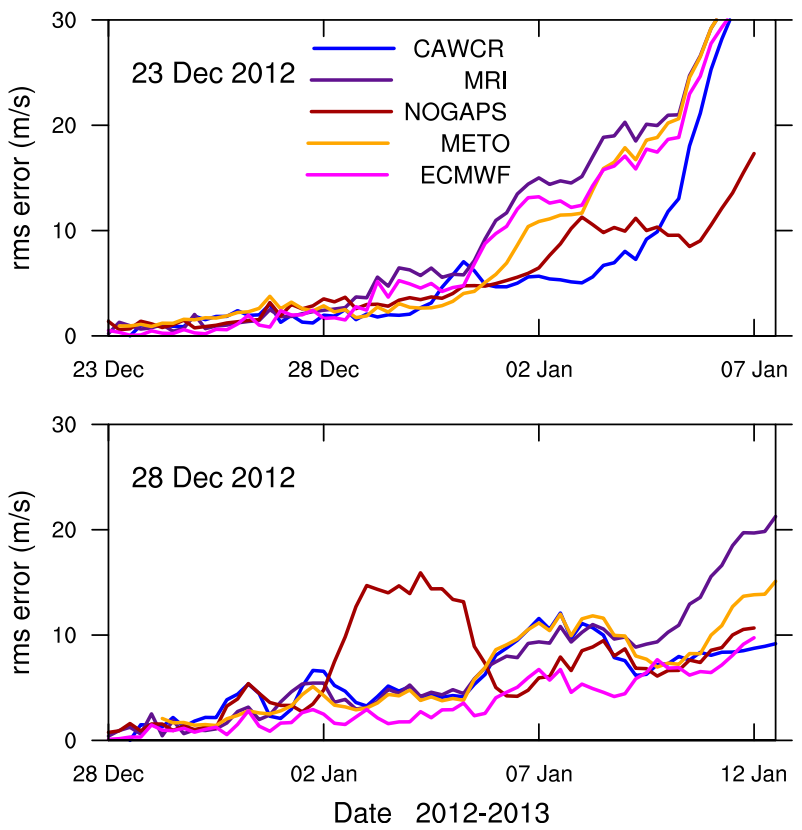

FIG. 2. Growth of forecast error measured as RMSE in the zonalmean zonal wind at $10 \mathrm{hPa}$ and $60^{\circ} \mathrm{N}$. The error is calculated against the corresponding ERA-Interim values for all ensemble members. The initialization dates are (top) 23 Dec $2012(D-15)$ and (bottom) 28 Dec $2012(D-10)$.

among the ensemble members. The vortex in MRI for $D-15$, however, moved over North America passing through the Atlantic. A slight westward movement of the vortex for $D-15$ was also seen in METO and ECMWF. Several members of the ECMWF ensemble for $D-15$ suggested an elongation of the vortex. During this period, the vortex in NOGAPS for $D-15$ had the typical characteristics of a displacement-type SSW with the vortex being significantly off the pole and elongated.

Although many of the model runs from the $D-15$ initialization show significant weakening of the zonalmean zonal wind, the cause of this weakening is associated with vortex displacement rather than the elongation and splitting seen in the ERA-Interim data. If, as suggested by Mitchell et al. (2013), the impact of stratospheric variability is dependent on the type of variability, then this divergence has important implications for the potential for gaining additional tropospheric predictability from the stratosphere.

The models initialized on 28 December $2012(D-10)$ resulted in two types of vortex behavior (Fig. 3b). By 7 January 2013, the vortices in CAWCR, MRI, METO, and ECMWF elongated along the northwestsoutheast line, typical of the most vortex-splitting events (Matthewman et al. 2009) as seen in the ERA-Interim. In contrast, the vortex in NOGAPS remains close to Eurasia. This bias explains an abrupt increase of RMSE 
(a)
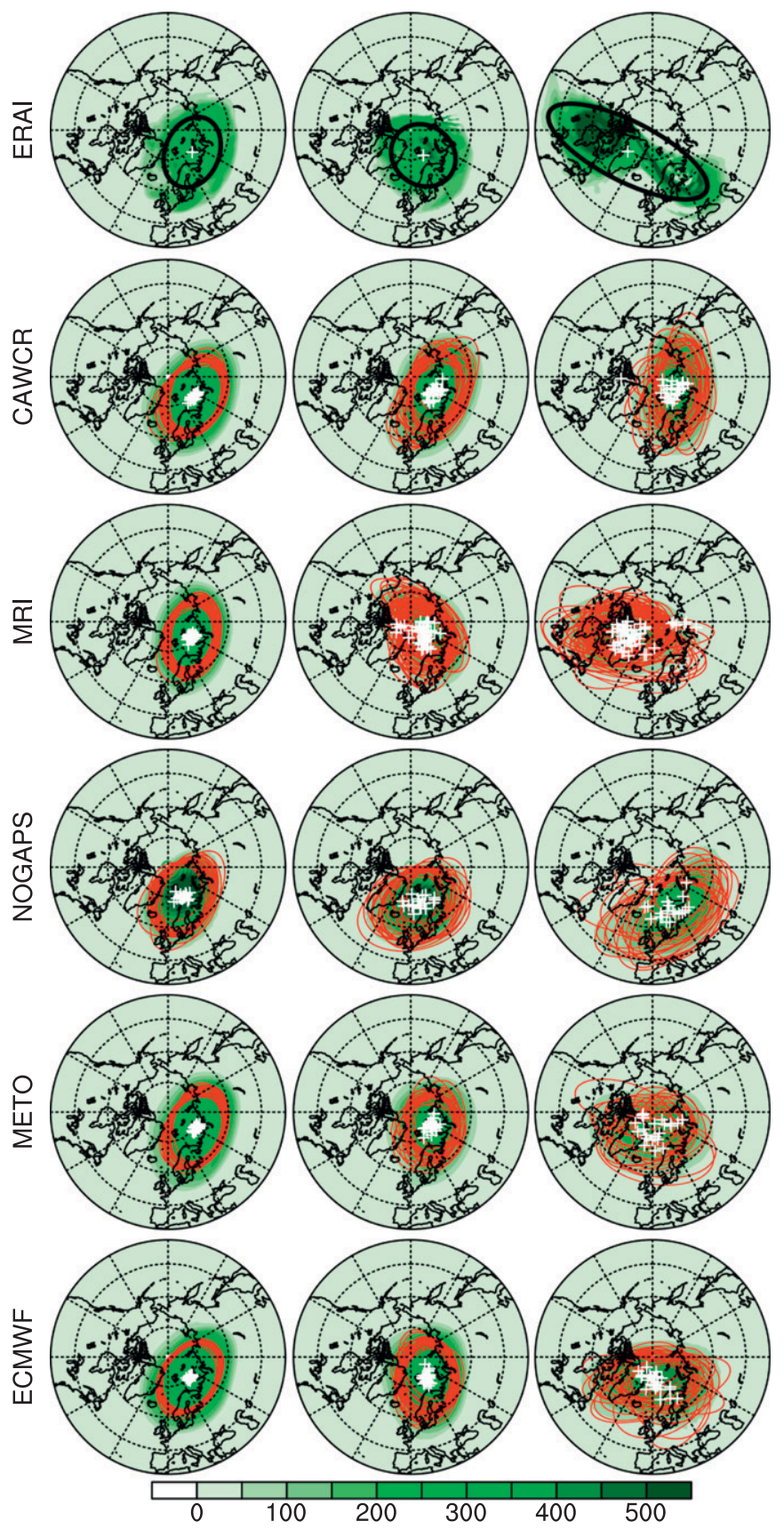

FIG. 3. (a) The evolution of the vortex on the 850-K isentropic levels as observed in (from top to bottom) ERA-Interim and the corresponding vortex structures simulated by the model ensemble members (CAWCR, MRI, NOGAPS, METO, and ECMWF) when models are initialized on 23 Dec $2012(D-15)$. Colored ellipses are the equivalent ellipse calculated using elliptical diagnostics. Green-filled contours denote the PV values relative to the mean PV values between $45^{\circ}$ and $90^{\circ} \mathrm{N}$ calculated by subtracting the mean PV value between $45^{\circ}$ and $90^{\circ} \mathrm{N}$ from modified PV [see Eq. (A1) of the appendix]. For models, the ensemble mean is plotted. PV values are in PV units (PVU; $1 \mathrm{PVU}=10^{-6} \mathrm{~K} \mathrm{~kg}^{-1} \mathrm{~m}^{2} \mathrm{~s}^{-1}$ ). White plus signs denote centroids of the equivalent ellipses. (b) As in (a), but for the initialization date of $28 \operatorname{Dec} 2012(D-10)$. 
(b)

30 DEC

O3 JAN

07 JAN
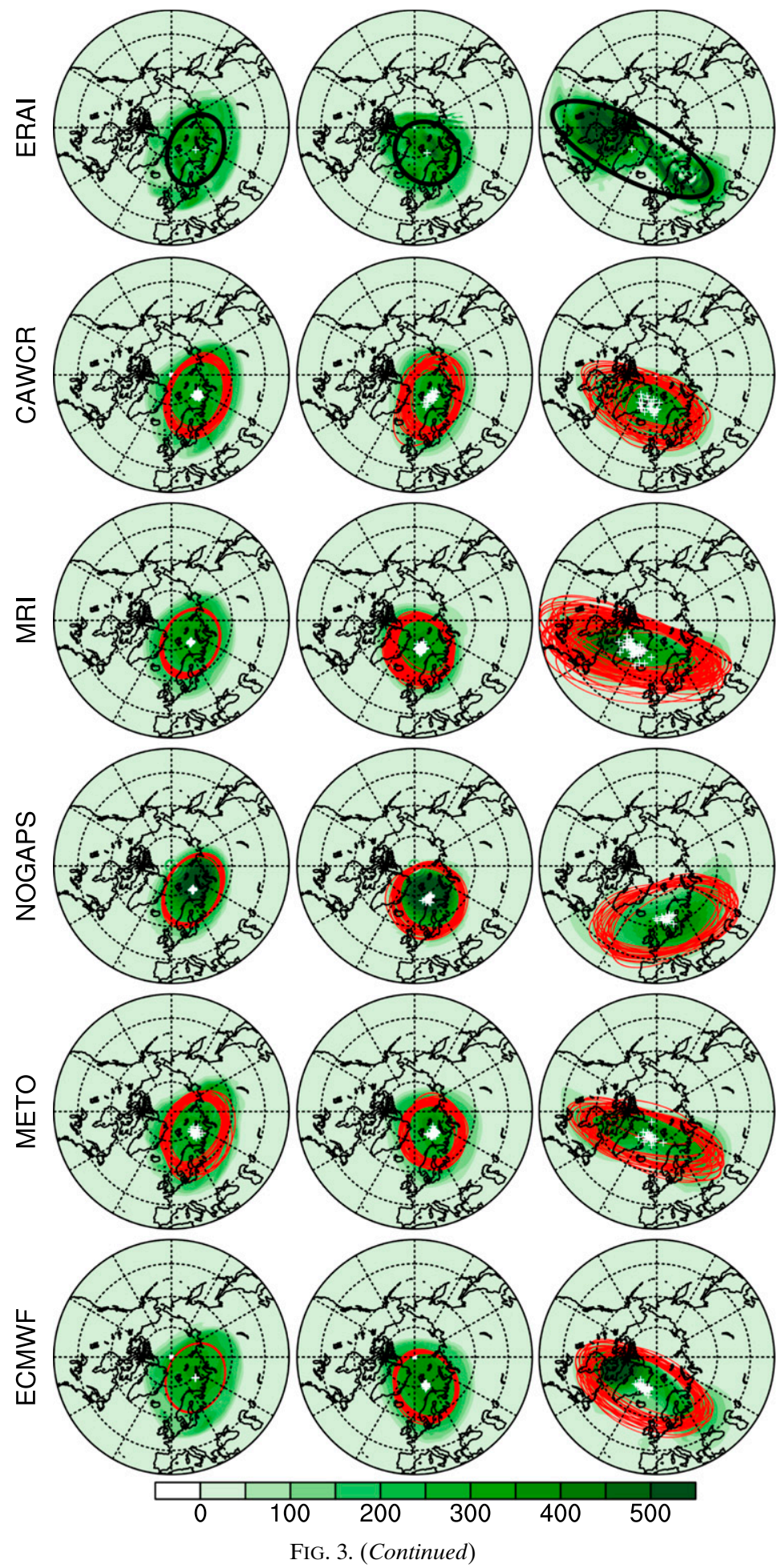
in NOGAPS for the $D-10$ initialization shown in the Fig. 2. It appears that different model vortices are excited by different wave dynamics. We will show in the next section that runs initialized at different lead times and in different models vary in their ability to amplify planetary waves 1 and 2 in the stratosphere.

\section{Limitations on the predictability}

\section{a. Wave amplification}

In this section, we examine the factors that limit the predictive skill of the five models at various lead times. We focus on the following issues identified in section 4:

- Most forecasts at 15-day lead times are unable to produce zonal-mean zonal wind deceleration around the time of the SSW.

- In cases when the model predicts a zonal-mean deceleration at a 15-day lead time, such as the NOGAPS model, the forecast type of stratospheric vortex disturbances are often different to that which actually occurred.

Figure 1a shows that for the $D-15$ initialization there is a large ensemble spread in all the models on 7 January 2013 and that a small number of ensemble members of MRI, NOGAPS, and METO were able to predict the SSW. We make use of this ensemble spread to examine the similarities and differences between the skillful and unskillful ensemble members in an attempt to understand the factors that limit the ability of modeling systems to predict the SSW.

We subjectively assign a number of ensemble members from each forecast into two groups, based on the evolution of zonal-mean zonal wind at $60^{\circ} \mathrm{N}$ and $10 \mathrm{hPa}$; the groups for $D-15$ and $D-10$ initializations are shown in Fig. 4. For most models, one group has significant zonal wind deceleration around 7 January 2013 (best group; BST), while the other group maintains a strong stratospheric jet (worst group; WST). Note that we selected members lying at the extreme ends of the ensemble spread and, therefore, not all members of the ensemble are included in these groups. Figure 4 also shows the ensemble mean of each group as thick solid (BST) and dashed (WST) curves.

To understand the contributions of the planetary waves of different scales to the stratospheric zonal wind behavior in different models, we calculated the vertical component of zonal-mean EP flux $\left(\overline{v^{\prime} T^{\prime}}\right) \mathrm{EP}_{z}$ for individual wave components. The mean $\mathrm{EP}_{z}$ between $45^{\circ}$ and $75^{\circ} \mathrm{N}$ at the vertical level of $100 \mathrm{hPa}$ in the stratosphere and the average between 700 and $600 \mathrm{hPa}$ in the troposphere are compared. The ERA-Interim calculation, when heat flux from all long waves (wavenumbers
1,2, and 3) are included (not shown), indicates that the growth in the longwave EP flux in the troposphere between 28 December 2012 and 2 January 2013 is reflected in the amplification of these waves in the stratosphere between 2 and 7 January 2013, leading to the SSW. Here we compare the model performance in producing wave1 and wave-2, separately, in the troposphere and corresponding amplification of these waves in the stratosphere.

Figure 5a shows the $\mathrm{EP}_{z}$ from ERA-Interim and different models for BST and WST members for $D-15$ initialization when only the wave- 1 component of the EP flux is retained. Likewise, Fig. 5b shows corresponding plots for the wave- 2 component. It is worth emphasizing here that the tropospheric wave activity in the time range from 28 December 2012 to 2 January 2013 should be compared to the stratospheric wave activity in the time range of 2-7 January 2013 to account for the approximately 5-day (Shaw et al. 2010) time of propagation of waves from the troposphere to the stratosphere. It is clear from the ERA-Interim curve that wave-1 amplification in the stratosphere peaked on around 2 January 2013 and then decreased (Fig. 5a); the wave-2 component, on the other hand, increased most rapidly after 2 January 2013 (Fig. 5b), which was associated with the splitting of the vortex.

In the midtroposphere, wave- $1 \mathrm{EP}_{z}$ for the BST members in all the models are, in general, larger than the $\mathrm{EP}_{z}$ for WST members for the $D-15$ initialization. This difference between BST and WST members is even more pronounced at the base of the stratosphere (Fig. 5a, top). A large (up to about $10 \times 10^{5} \mathrm{~km} \mathrm{~s}^{-1}$ ) difference of total $\mathrm{EP}_{z}$ at $100 \mathrm{hPa}$ between the BST and WST members is particularly evident for MRI, METO, and ECMWF. The agreement with ERA-Interim shows that the BST members better capture the vertical propagation of the amplified planetary wave- 1 in the troposphere as well as in the stratosphere for $D-15$ initialization. CAWCR predicts a rather weak amplification of wave- $1 \mathrm{EP}_{z}$ in the troposphere as well as in the stratosphere, which is reflected in the very weak deceleration of the zonal-mean zonal wind in the CAWCR forecast for the $D-15$ initialization even for their BST members.

Though there are large differences among models and observations in the tropospheric component of wave-2 $\mathrm{EP}_{z}$, the difference is not as pronounced as the stratospheric component, particularly between 2 and 7 January 2013 (Fig. 5b). The BST members of CAWCR (Fig. 5b) overestimate the tropospheric wave-2 component of $\mathrm{EP}_{z}$ during this period. However, none of the models were able to reproduce the excessive amplification of wave- 2 in the stratosphere for $D-15$ initialization. Comparing Figs. $5 \mathrm{a}$ and $5 \mathrm{~b}$ we notice that the 
D-15
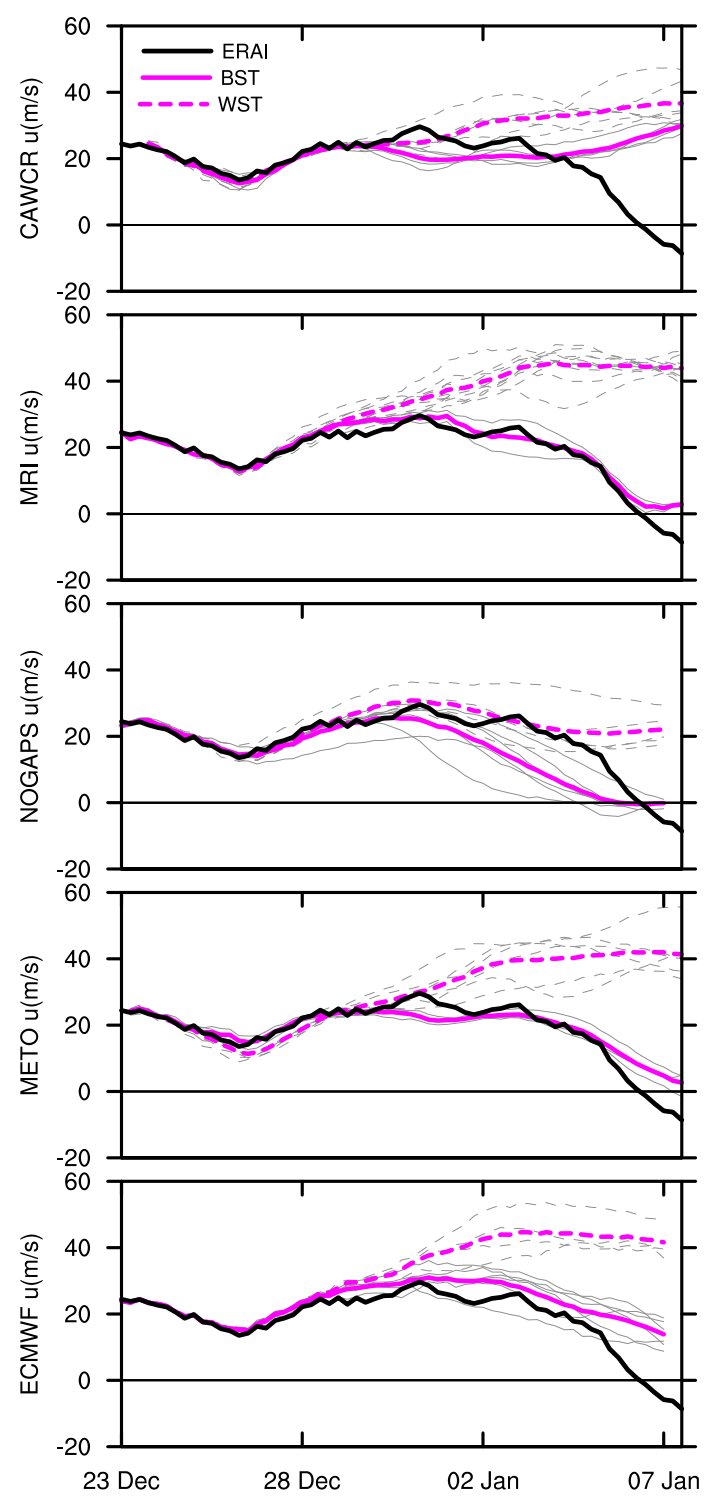

D-10
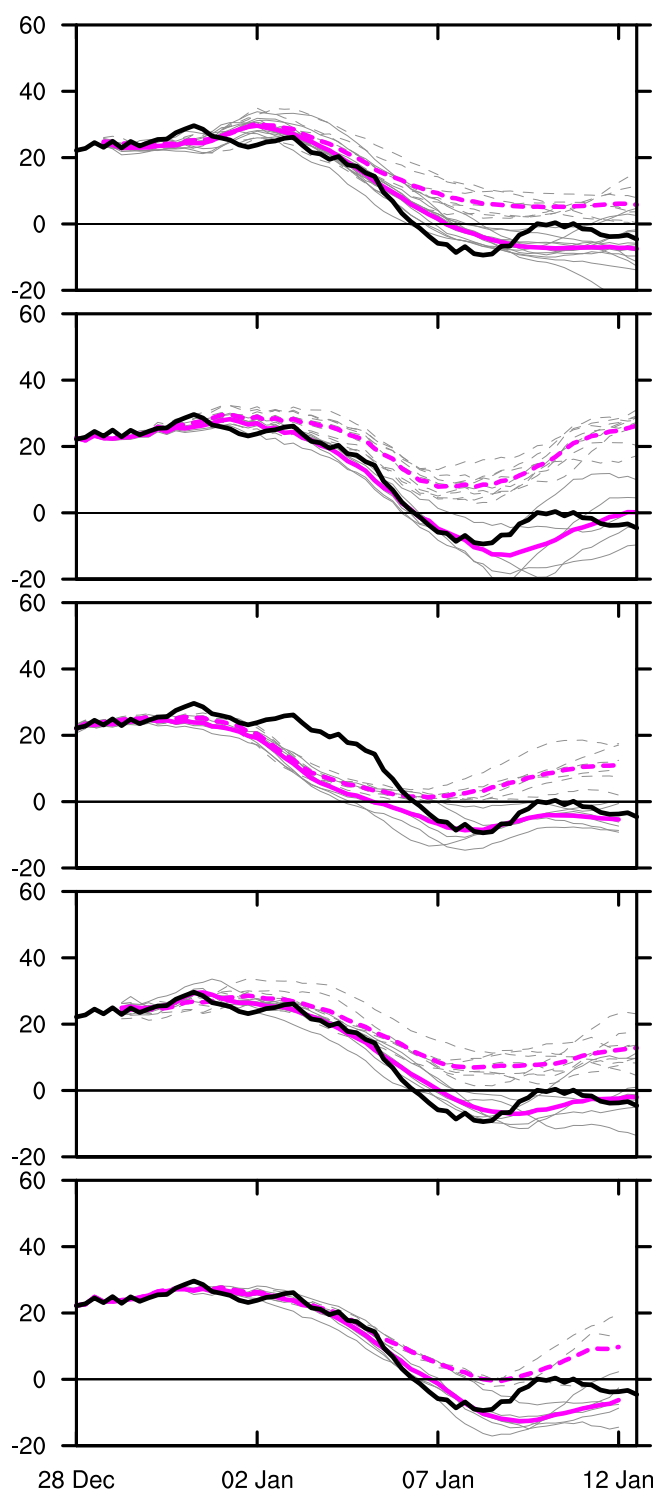

FIG. 4. Selected BST (solid curve) and WST (dashed curve) members for all models for two initializations: (left) $D-15$ and (right) $D-10$. Thick curves represent the mean of each subensemble.

BST and the WST members of different models differ mostly in their wave-1 amplification and not in their wave- 2 amplification, in the troposphere as well as in the stratosphere. This indicates that the reason for the BST members of some models forecasting the SSW on $D-$ 15 initializations is the wave- 1 amplification.

Similar analyses of the $D-10$ initialization with another set of BST and WST members is shown in Figs. 6a and $6 \mathrm{~b}$ for the wave- 1 and wave- 2 components of $\mathrm{EP}_{z}$, respectively. Note that here we compare the period from 28 December 2012 to 2 January 2013 in the troposphere to the period of 2-7 January 2013 in the stratosphere.
If we compare the wave- 1 and wave- 2 contributions to the anomalous stratospheric flow in Figs. 6a (top) and 6b (top), we find that CAWCR and MRI have larger contributions from wave-1 whereas ECMWF, NOGAPS, and METO have the major contribution from wave-2 amplification, for the $D-10$ initialization. In fact ECMWF appears to closely follow ERA-Interim for wave-1 as well as wave- 2 in the stratosphere up until 7 January 2013. CAWCR performed worst for the wave-2 amplification in the stratosphere despite amplifying wave-2 in the troposphere correctly, for the $D-10$ initialization. 
(a)
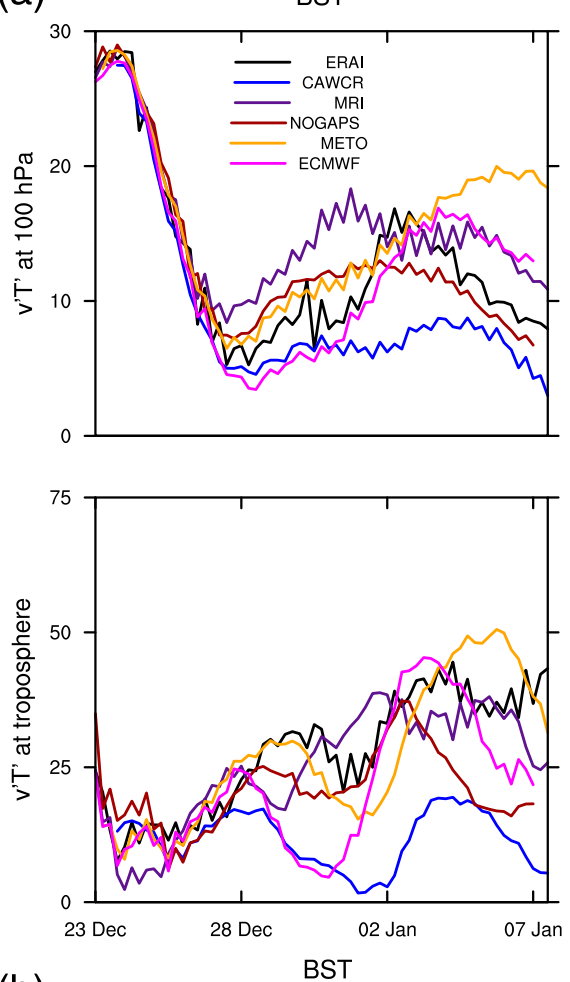

(b)
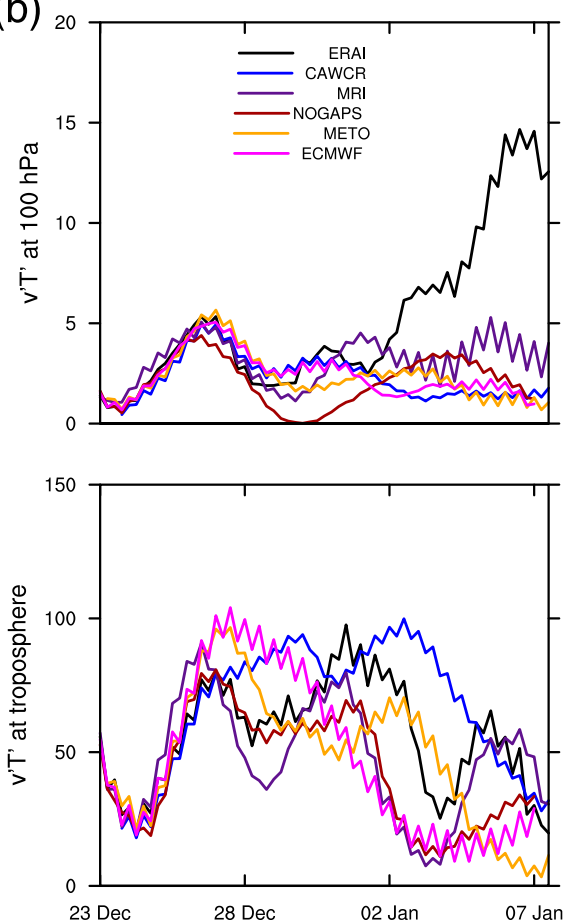
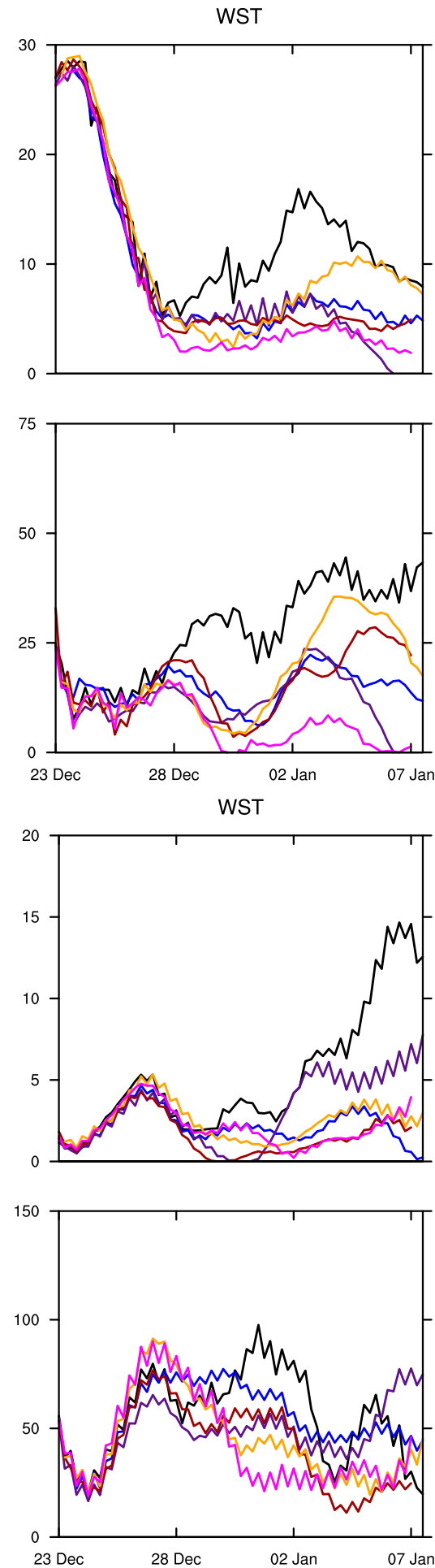

FIG. 5. (a) (top) The ensemble mean of the wave-1 vertical component of $\overline{v^{\prime} T^{\prime}}$ (EP flux) in the stratosphere at $100 \mathrm{hPa}$ averaged between $45^{\circ}$ and $75^{\circ} \mathrm{N}$ for (left) BST and (right) WST members for the initialization date of 23 Dec $2012(D-15)$. Black curve denotes corresponding ERA-Interim values. (bottom) As in (top), but for the troposphere averaged between vertical levels of 700 and $600 \mathrm{hPa}$ and averaged between $45^{\circ}$ and $75^{\circ} \mathrm{N}$. The $y$-axis unit is $10^{5} \mathrm{~K} \mathrm{~m} \mathrm{~s}^{-1}$. In this figure and Fig. 6b, compare sections between $28 \mathrm{Dec} 2012$ and $2 \mathrm{Jan} 2013$ of the troposphere (bottom) to the section between 2 Jan 2013 and 7 Jan 2013 of the stratosphere (top). (b) As in (a), but for only wavenumber 2. 
(a)
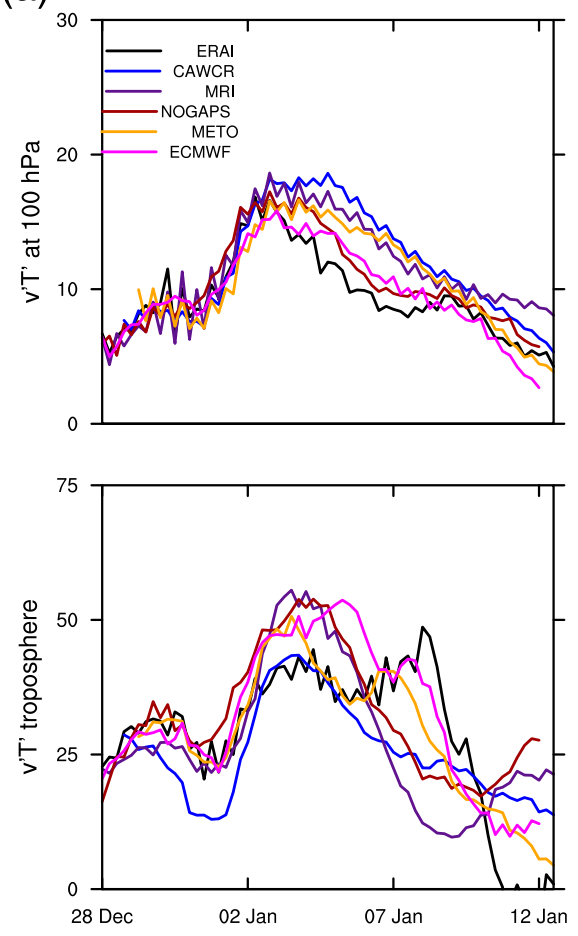

(b)
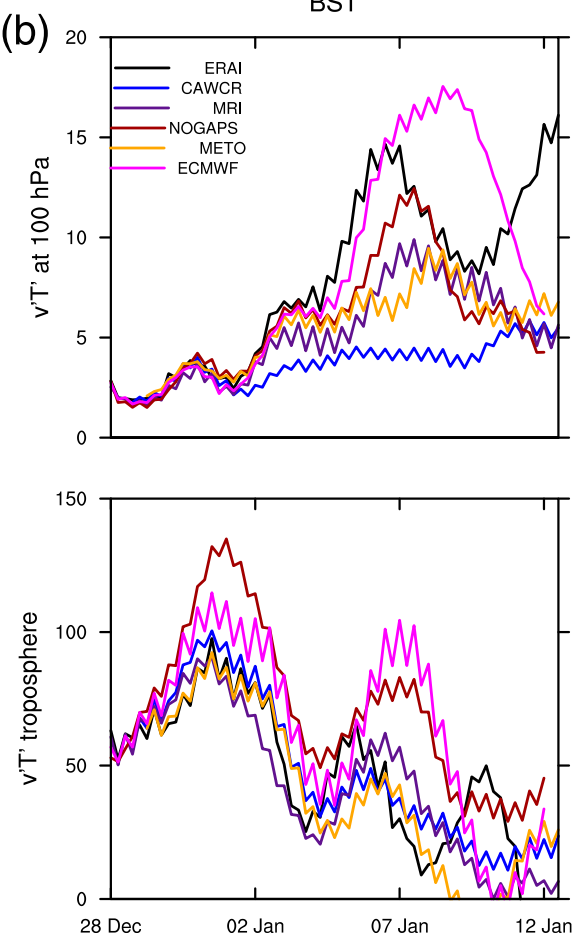

WST
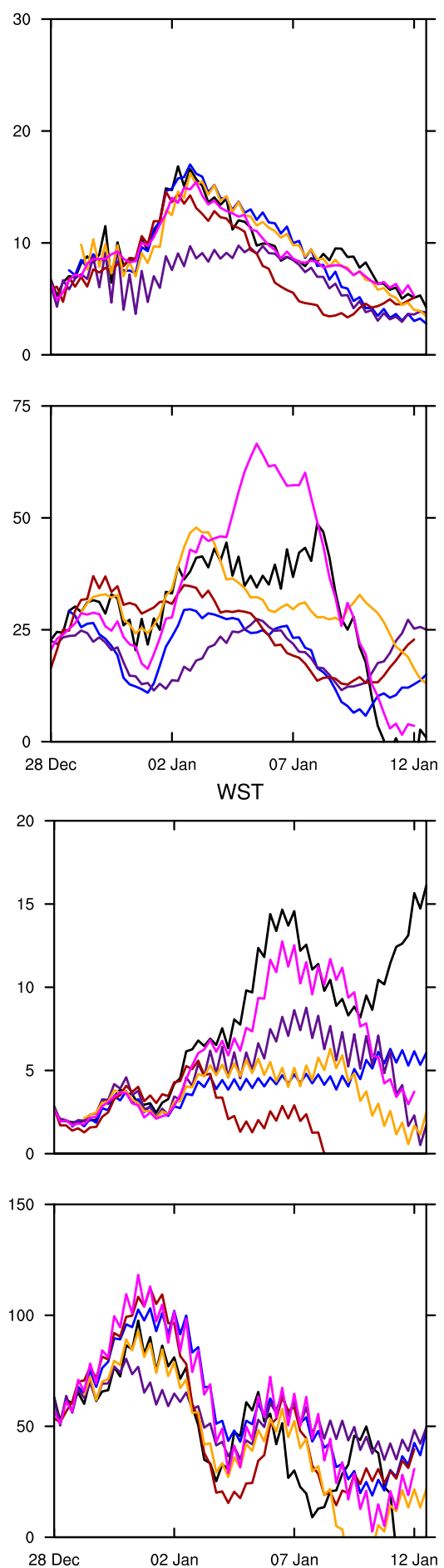

FIG. 6. (a) As in Fig. 5a, but for the initialization date of 28 Dec 2012 ( $D$ - 10). In (a) [and in (b)], compare sections between 28 Dec 2012 and 2 Jan 2013 of the troposphere (bottom) to the section between 2 Jan 2013 and 7 Jan 2013 of the stratosphere (top). (b) As in Fig. 5b, but for only wavenumber 2 . 
In summary, the ERA-Interim data show that the vortex-splitting event of 7 January 2013 is associated with the tropospheric wave- 2 amplification between 28 December 2012 and 2 January 2013. This tropospheric wave- 2 component propagated into the stratosphere between 2 and 7 January 2013. Although most of the models were able to forecast the tropospheric amplification, they failed to reproduce the observed evolution of wave-2 in the stratosphere in the $D-15$ initialization for both BST and WST members.

\section{b. Vortex geometry}

The differences in planetary wave propagation, outlined above, strongly influence the evolution of the polar vortex structure in the BST and WST members as shown in Fig. 7. For the $D-15$ initialization, the vortices of the BST members of all the models show an elongation around the time of the SSW (5-7 January 2013, here only for 7 January 2013 is shown). The BST members of MRI for $D-15$ initialization closely resemble the ERAInterim orientation but miss the wave- 2 splitting, emphasizing the lack of wave- 2 amplification (Fig. 5b) and the excess of wave-1 amplification (Fig. 5a) in the stratosphere. Thus, the BST members of MRI show a mixed response of some splitting- and mostly displacement-type SSWs, linked to the overestimation of wave-1 seen in Fig. 5a. The BST members of METO for the $D-15$ initialization have a similar vortex orientation but fail to reproduce the vortex elongation seen in ERA-Interim.

Only one member of the BST ensemble of ECMWF has an orientation similar to the ERA-Interim orientation in $D-15$ initialization, but the mean vortex remains centered over Europe. All other members of the BST ensemble of ECMWF for $D-15$ initialization show a typical wave-1-induced vortex displacement away from the pole (but without the correct vortex orientation).

The elongation, displacement, and orientation of the BST members of CAWCR and NOGAPS for the $D-$ 15 initialization were quite different to that of the BST members of METO, ECMWF, and MRI. Their vortex center longitudes differ significantly from ERA-Interim; the NOGAPS longitudes have a larger separation from the pole representing a displacement-type warming induced by strong wave- 1 amplification. The stratospheric wave- 1 amplification of the BST members of NOGAPS for the $D-15$ initialization peaked on 3 January 2013 and then started decreasing afterward, showing early displacement-type warming (Fig. 5a).

Thus, although the BST members of the three models (METO, MRI, and NOGAPS) predict an SSW for the $D-15$ initialization, Fig. 7 shows that the SSW predicted by these models are of a different type to that represented in the ERA-Interim. The vortices of the corresponding WST members of the models for the $D-15$ initialization, in general, are centered on the pole and circular (though smaller in size than the BST members), particularly the WST members of MRI and METO. The vortices of the WST members of NOGAPS for the $D-15$ initialization are slightly elongated, but still closer to the pole than their BST counterparts.

Now we consider the $D-10$ initialization shown in Figs. $7 \mathrm{c}$ and $7 \mathrm{~d}$. The BST members of MRI, METO, and ECMWF are generally in better agreement with ERAInterim in simulating the orientation and elongation of the vortex in comparison to the BST members of CAWCR and NOGAPS. The BST members of CAWCR for $D-10$ initialization failed to represent the elongation of the vortex, and there was little difference between the BST and WST members of the model. As noted in the $\mathrm{EP}_{z}$ analysis of $D-10$ forecast, CAWCR overestimated the amplitude of wave- $1 \mathrm{EP}_{z}$ in the stratosphere and had the least wave- 2 amplification compared to all other models. This highlights the importance of the stratospheric wave-2 amplification in the elongation of vortex.

The vortices of the BST members of NOGAPS in the $D-10$ initialization are displaced farther from the pole than other models (cf. centroid average latitude of $\sim 62^{\circ} \mathrm{N}$ for NOGAPS vs $\sim 68^{\circ}-72^{\circ} \mathrm{N}$ for the other models) and exhibit a notably different orientation. The large elongation of the NOGAPS vortices may be related to the model's ability to amplify wave- 2 in the stratosphere for the $D-10$ initialization as shown in Fig. 6 b.

The ECMWF forecast for the $D-10$ initialization most closely predicts the vortex geometry of the ERAInterim dataset, producing two distinct vorticity centers in the ensemble mean of its BST as well as in its WST members. In general, the WST members for the $D-10$ initialization in all models showed the same evolution as the corresponding BST members, but with slightly lower amplitude. All members of all the models in the $D-10$ initialization behaved similarly (as is also apparent in the spaghetti plots in Figs. 1) with less spread than the $D-15$ forecasts. Analysis of the time series of area, aspect ratio, and centroid latitude of the vortices for the $D-15$ and $D-10$ forecasts (not shown) shows that the differences between the BST and WST members, highlighted above, develop rapidly around the time of the SSW (between 3 and 4 January 2013).

\section{c. Tropospheric blocking and stratospheric initial state}

Next we examine the tropospheric evolution in the BST and WST ensembles of each model in an attempt to understand the difference in planetary wave evolution between the two groups. Figure 8 shows the ensemble 
(a) D-15 BST

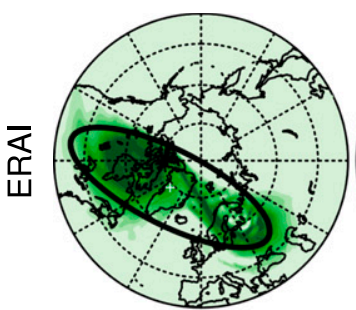

(b) D-15 WST

(c) D-10 BST

(d) D-10 WST
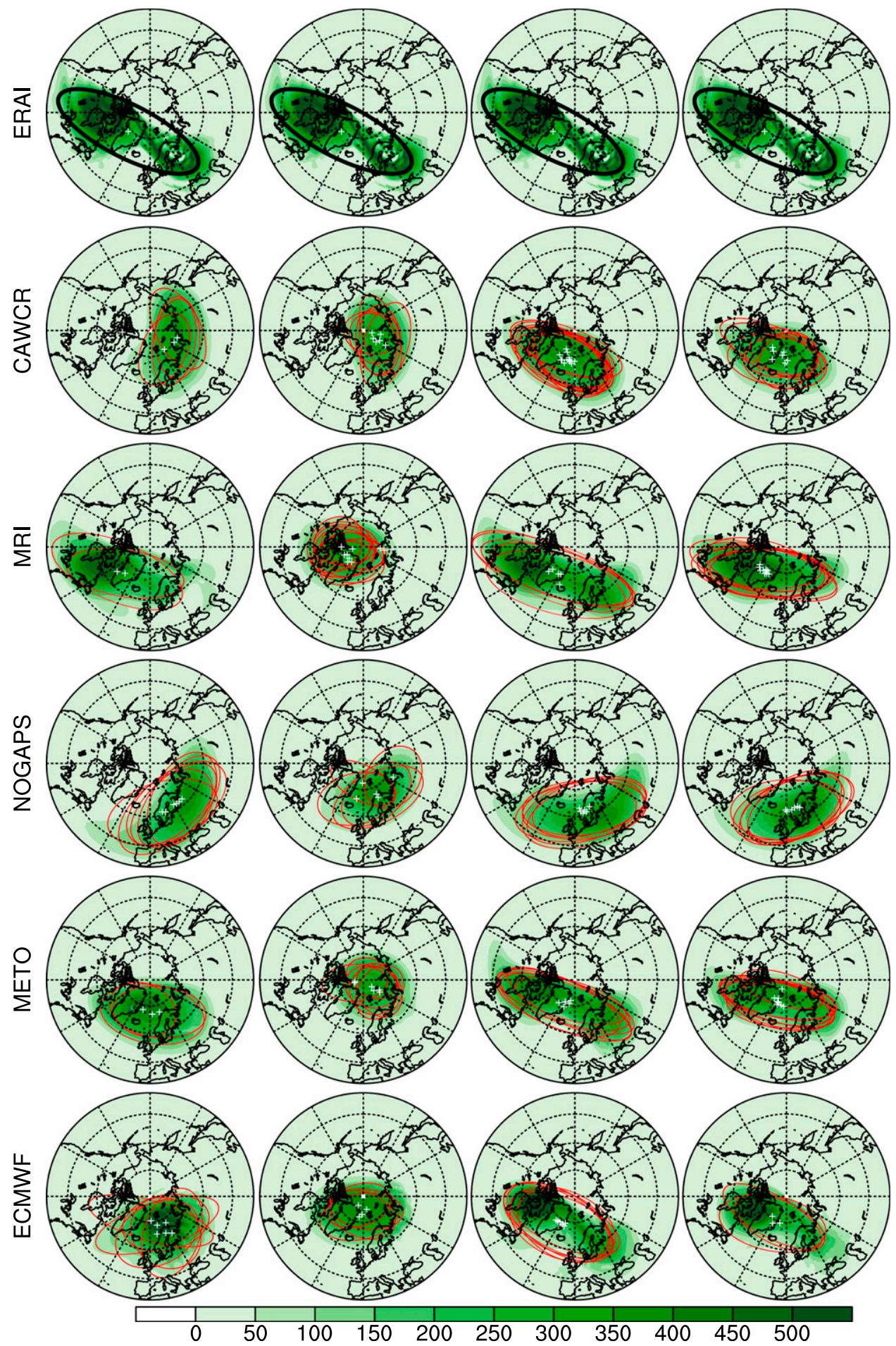

FIG. 7. Vortex structure on 7 Jan 2013 at $850-\mathrm{K}$ isentropic levels simulated by the (a) BST and (b) WST members when the models are initialized on 23 Dec $2012(D-15)$. (c),(d) The BST and WST members on 7 Jan 2013 when initialized on 28 Dec $2012(D-10)$. Curves and contours have the same meaning as in Fig. 3a. (top) ERA-Interim, which is repeated for ease of comparison. Filled green contours shows PV values (PVU) as in Fig. 3. White plus signs denote centroids of the equivalent ellipses. 
mean $500-\mathrm{hPa}$ geopotential height averaged between 31 December 2012 and 2 January 2013 for the $D-15$ and $D-10$ experiments for BST and WST members. It is clear from Fig. 8 (top) that there was a typical wave-2 structure in the troposphere with strong ridges in the eastern North Pacific and North America and Eurasia prior to the SSW, associated with the amplification of the wave- $2 \mathrm{EP}_{z}$ in the troposphere.

For the $D-15$ experiment, CAWCR was somewhat successful in forecasting this pattern and was among the best models, but the model failed to reproduce the amplification of $\mathrm{EP}_{z}$ in the stratosphere or to reproduce the correct stratospheric vortex structure. MRI, which predicted the correct vortex orientation for a vortexsplitting SSW in its BST members, also successfully forecasted the Eurasian block, but failed to reproduce this block in its WST members. Thus, in the case of MRI, we see a clear difference between the BST and WST members for the association between the blocking and SSW in the $D-15$ initialization.

For the $D-10$ initialization, all the models (except MRI) successfully predict the tropospheric blocking structure, and there is almost no difference between their BST and WST members. At the 10-day lead time, differences in predicting the SSW among different models and different ensemble members are, therefore, more strongly linked to the amplification of wave- 2 in the stratosphere.

To further understand the inability of some models to amplify wave-2 in the stratosphere, we looked at the 3-day mean initial zonal-mean wind field for the biases against ERA-Interim wind (figure not shown here). We found a significant positive upper-stratospheric zonal-mean zonal wind bias in CAWCR and a negative bias in NOGAPS. These two models also produce the least skillful forecasts of wave-2 $\mathrm{EP}_{z}$ in the lower stratosphere. MRI and ECMWF were initialized with the least bias in the stratosphere, for $D-15$ as well as $D-10$ initialization. For the $D-10$ initialization, however, the ECMWF forecast of the tropospheric circulation during $31 \mathrm{De}-$ cember 2012 and 2 January 2013 was more skillful than that of MRI (Fig. 8). This accurate initialization, at least for the zonal-mean zonal wind, and the forecasting skill of tropospheric circulation likely contributed to the skill of ECMWF to forecast the SSW. We, however, need to be cautious in attributing models' failure or success in simulating wave- 2 amplification to the initial wind bias against ERA-Interim because of the veracity of the ERAInterim wind itself at these levels. Many studies have shown bias in the ERA-Interim wind at the upperstratospheric levels following elevated stratopause events (Manney et al. 2008; Hitchcock and Shepherd 2013). NOGAPS also has strong wind biases in the upper stratosphere, which may have contributed to the early onset of the SSW in the NOGAPS forecast for the $D-15$ initialization (e.g., Marshall and Scaife 2010).

\section{d. Regression analysis}

Finally, we try to find phenomena and regions sensitive to the forecast results using regression analysis. We make use of the large ensemble spread for the $D-15$ forecasts shown in Figs. 1 and 7. Mukougawa et al. (2005) showed a high sensitivity of the SSW event in 2001 to the zonal wind anomaly in the upper troposphere associated with the Atlantic blocking. Here we show the correlation between the anomaly in the stratospheric wind and the anomaly in the tropospheric blocks, by calculating regression coefficients of 500-hPa geopotential heights and of EP fluxes against the zonal-mean zonal winds at $60^{\circ} \mathrm{N}$ and $10 \mathrm{hPa}$ on 7 January 2013, using the ensemble members of the $D-15$ initialization. As the weaker westerly winds correspond to stronger SSWs, all regression coefficients have been multiplied by -1 .

Figure 9 shows the regression of 3-day mean $500-\mathrm{hPa}$ geopotential height on 29 December 2012, 1 January 2013 , and 4 January 2013 , against the $10-\mathrm{hPa} 60^{\circ} \mathrm{N}$ zonalmean zonal wind. In ERA-Interim (Fig. 9, top), a blocking anomaly developed over north-central Siberia from 29 December 2012 to 1 January 2013. For the period from 29 December 2012 to 1 January 2013, significant positive regression coefficients are found over Europe around $60^{\circ} \mathrm{N}$ in all of the models. This signal, however, is weak for CAWCR on 29 December 2012, but became stronger on 1 January 2013. This means that the members of the ensemble that developed a strong blocking high also produced a stronger SSW. However, the peak positions of the blocking high differ from one model to the other: METO and NOGAPS tend to have signals around $0^{\circ}-40^{\circ} \mathrm{E}$ from 29 December 2012 to 1 January 2013, but CAWCR, MRI, and ECMWF have signals around $50^{\circ}-60^{\circ} \mathrm{E}$ on 29 December 2012 with a shift to $10^{\circ} \mathrm{W}-0^{\circ}$ on 1 January 2013 . Weaker negative signals can also be found on the equatorial side of the positive signals in NOGAPS and METO, which are typical for blocking events (since they represent a reversal of the local height gradient).

Figure 10 shows the corresponding regression results for the EP flux and its divergence. On 1 January 2013, all models have upward EP flux signals centered at around $70^{\circ} \mathrm{N}$ and $10 \mathrm{hPa}$. As the forecast progresses, the size of the regression coefficients grows, suggesting that the EP flux is a strong determinant of the strength of the deceleration of the zonal wind, as discussed earlier (Fig. 5). The deceleration signals of zonal wind in the midlatitudes of the middle-upper stratosphere on 1 January 2013 are seen in METO and MRI. A deceleration 
(a)

D-15 BST

(b) D-15 WST
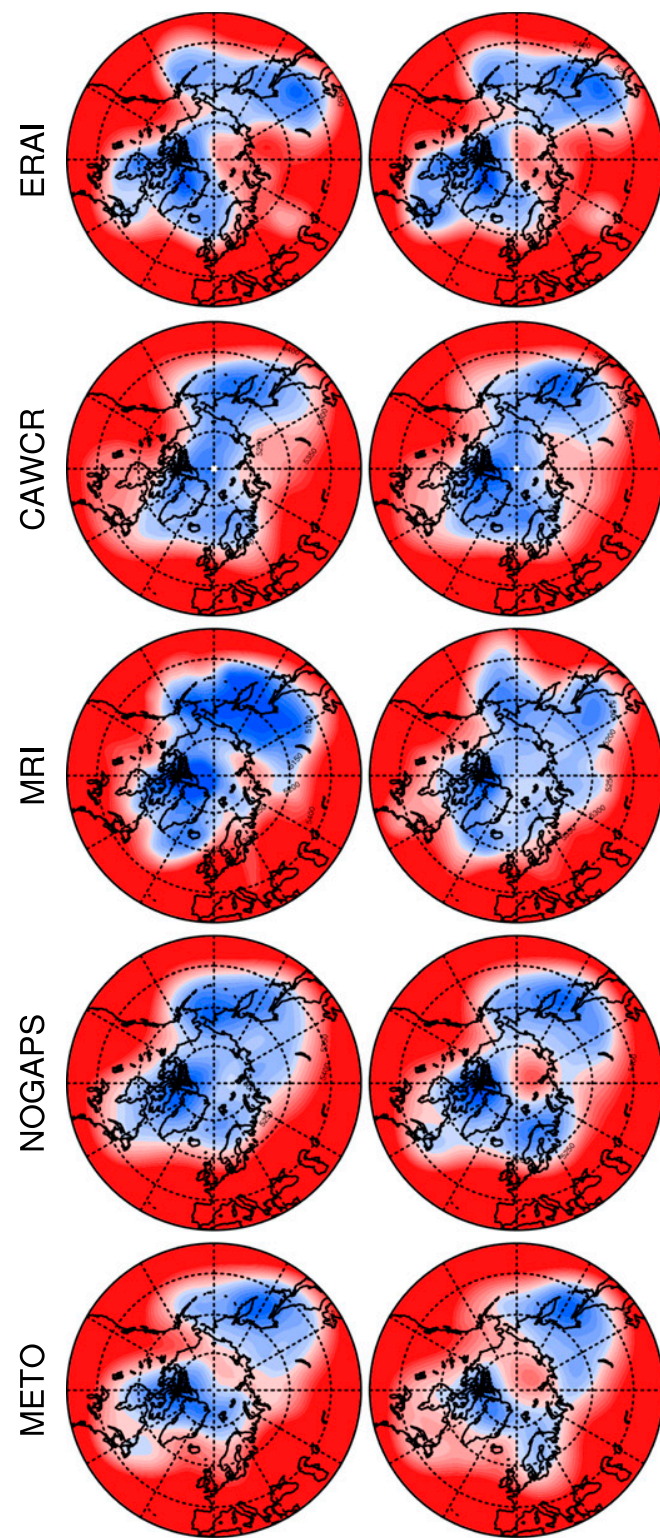

$\sum_{\circlearrowright}^{\amalg}$
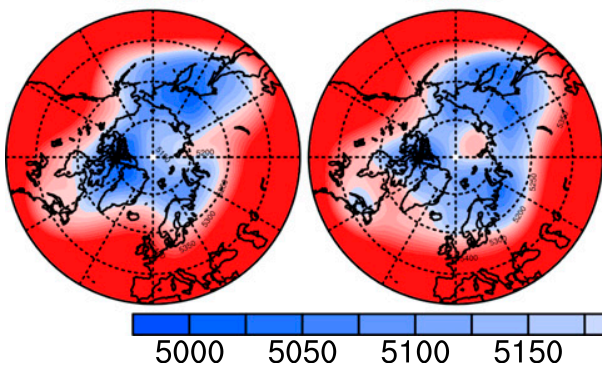

(c) D-10 BST
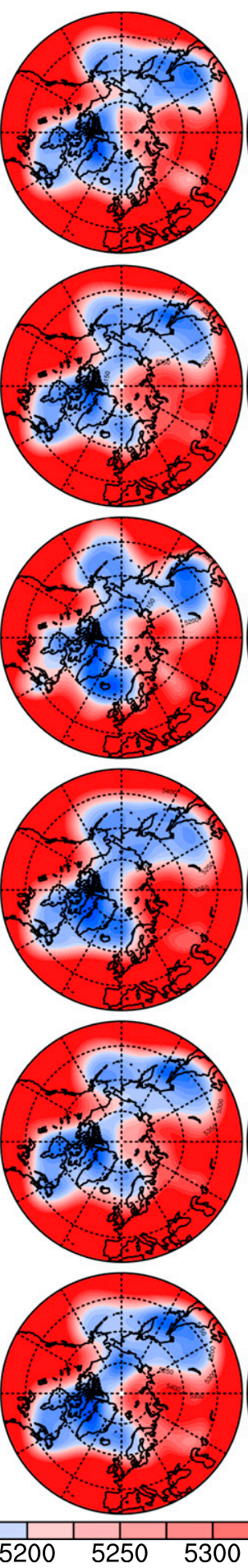

FIG. 8. 500-hPa geopotential height in (from top to bottom) ERA-Interim and the models (CAWCR, MRI, NOGAPS, METO, and ECMWF) averaged from 31 Dec 2012 to 2 Jan 2013 for models initialized on (a),(b) 23 and (c),(d) 28 Dec 2012. The averages of the BST ensemble members are given in (a),(c) and the averages of the WST members are given in (b),(d). The numbers in the color bar indicate geopotential height $(\mathrm{m})$. 

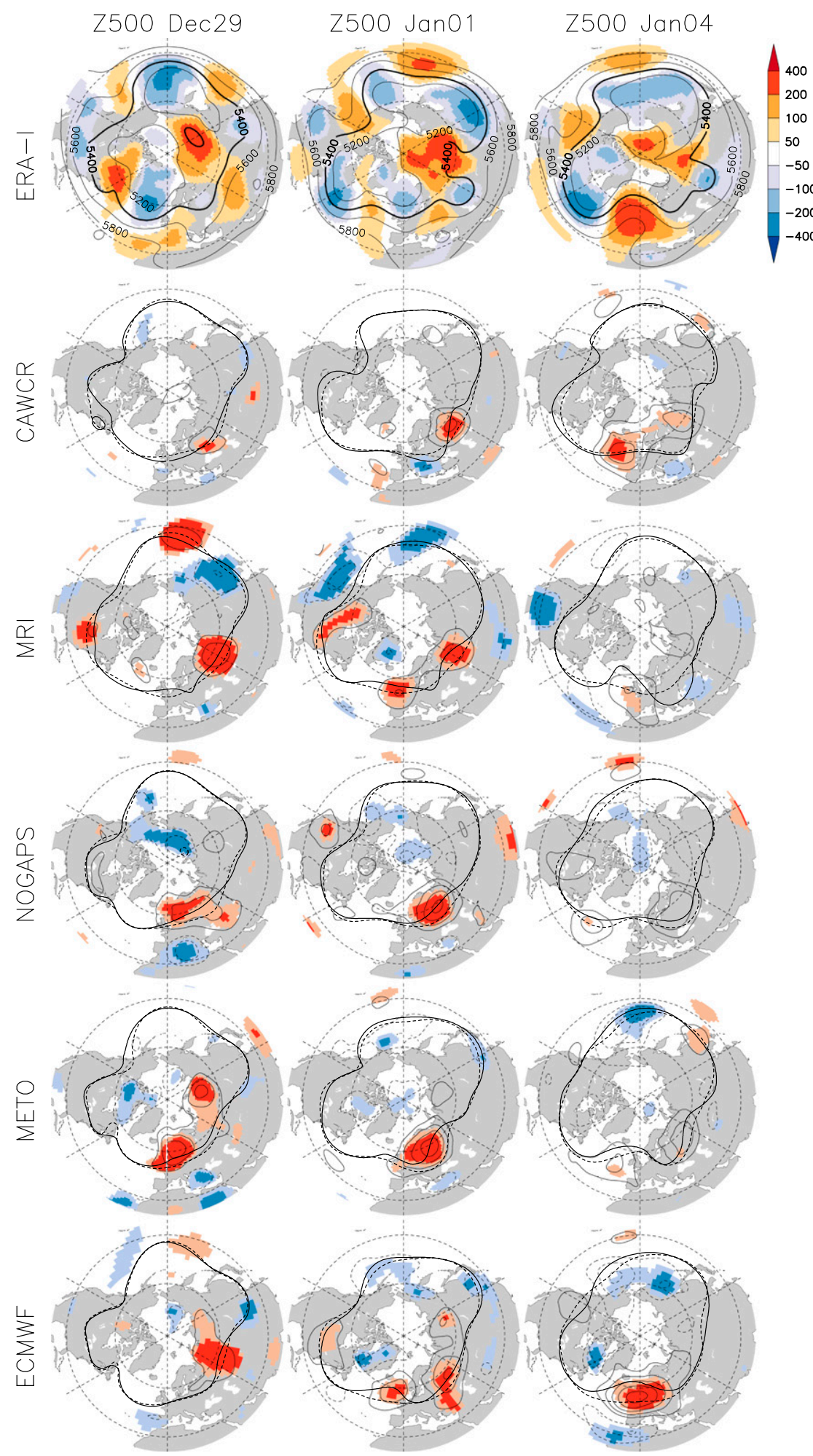

FIG. 9. (top) 500-hPa geopotential height (contours) and its anomaly from the climatology of 1979-2008 (shading), for ERA-Interim. (from second row to bottom) Regression coefficients of 500-hPa geopotential height on the zonal-mean zonal winds at $60^{\circ} \mathrm{N}$ and $10 \mathrm{hPa}$ on 7 Jan 2013. Patterns with the opposite sign are shown. Statistically significant regions are shaded (light shaded: $95 \%$, dark shaded: $99 \%$ ). Data of 3-day running mean are used. Red (blue) contours are the averages of BST (WST) members of $5400 \mathrm{~m}$. 

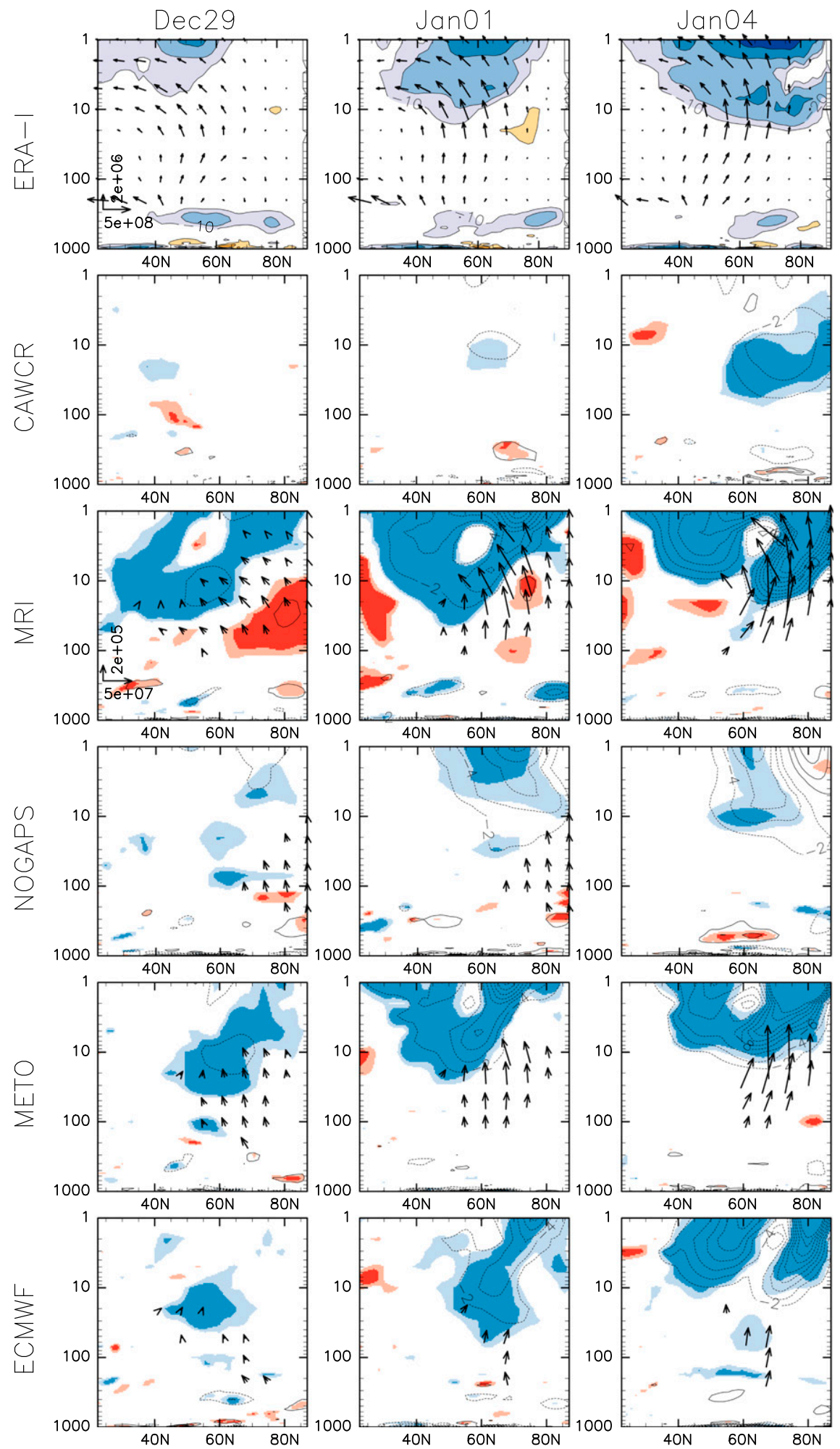

FIG. 10. (top) EP flux (arrows) and acceleration by EP flux divergence (contours and shading), for ERA-Interim. (from second row to bottom) Regression coefficients of EP flux (arrows) and acceleration by EP flux divergence (contours) on the zonal-mean zonal winds at $60^{\circ} \mathrm{N}$ and $10 \mathrm{hPa}$ on $7 \mathrm{Jan} 2013$. Patterns with the opposite sign are shown. Statistically significant regions of the acceleration are shaded (light shaded: 95\%, dark shaded: $99 \%$ ). Data of 3-day running mean are used. 
anomaly around the same region can be found in ERAInterim. The signals move poleward and are found in all models on 4 January 2013, corresponding to the signals for the zonal wind (Fig. 10).

In CAWCR, the EP flux signal appeared late on 4 January 2013, which is consistent with Fig. 10 where the correlation between tropospheric blockings and wind weakening also developed late, and consequently none of the members produced an SSW. Thus, although CAWCR did forecast blocking with reasonable success (Fig. 8, $D-15$ initialization), the blocks are not associated with enhanced EP flux (Fig. 10), so do not contribute to the wind weakening and have the least correlation with the stratospheric wind weakening (Fig. 9). In the case of NOGAPS, an SSW is produced by a significant number of members, but the significant EP flux divergence signal in Fig. 10 is weak compared to the signals in MRI, METO, and ECMWF.

In summary, for some models (MRI, METO, and ECMWF), members with higher geopotential anomalies over Europe about a week before the SSW tend to have stronger upward EP flux in the stratosphere, and produce larger deceleration of the zonal-mean zonal wind in the midlatitude. This correlation between blocking and the SSW, however, does not establish cause and effect, as some models (CAWCR) produce blocking, but not the SSW.

\section{Conclusions}

The experimental data from five different operational ensemble forecasting systems are analyzed and validated against ERA-Interim to study the predictability of the vortex-splitting SSW, which occurred on 7 January 2013. To our knowledge, this is the first time that a multimodel coordinated case study of the predictability of an SSW event has been conducted. The ability of models to predict the onset of easterly winds at $60^{\circ} \mathrm{N}$ and $10 \mathrm{hPa}$ is compared for forecasts initialized 15,10 , and 5 days before the SSW event. A few ensemble members of forecasts from MRI (2 out of 51), METO (3 out of 22), and ECMWF ( 6 out of 25) show a splitting tendency 15 days before the event. At 10 days before the event all the models successfully predicted that a strong weakening of the polar vortex would occur in early January 2013, but the models differed in their estimates of the timing of the wind reversal at $60^{\circ} \mathrm{N}$ and $10 \mathrm{hPa}$, the percentage of ensemble members that predicted a wind reversal, and the detailed vortex evolution.

Analysis of both the vortex structure and a proxy for the vertical component of the EP flux showed that all the models except ECMWF underestimated the amplification of wave- 2 planetary waves at the base of the stratosphere, despite successfully generating wave-2 planetary waves in the midtroposphere. This forecast error is particularly apparent at longer lead times, and results in a predominance of vortex-displacement SSW events. In contrast, all the models are able to reproduce the amplification of wave- 1 planetary waves in the stratosphere even at longer lead times.

For forecasts initialized 15 days before the SSW, there are weak indications of a link between a model's ability to predict tropospheric blocking and stratospheric vortex splitting, particularly for the BST members of MRI. Predicting tropospheric blocking may be a necessary but not sufficient condition for accurately predicting the SSW; for example, CAWCR failed to predict the SSW accurately despite successfully forecasting the tropospheric blocking several days before the event. Accurate stratospheric initial conditions may also be critical for SSW prediction, as the models that predicted the SSW accurately also tended to have lower-stratospheric initial bias in zonal-mean zonal wind.

In the future, it would be interesting to perform detailed analysis to see what actually limits wave propagation and breaking (particularly wave-2) in the stratosphere (e.g., is it a problem with the phasing of the climatological and forced waves?) It would also be interesting to investigate what role models' stratospheric grid spacing and models' tops have played in their predictive skill. There is a wide disparity in the vertical grid spacing of the models, from only 42 levels in NOGAPS to the 91 levels in ECMWF. Similarly, this ensemble can also be used to investigate how errors in the stratospheric forecast affect the troposphere; for example, do the BST members forecast a more accurate development of tropospheric annular mode anomalies than the WST members? While we plan some additional analysis of this type, we also encourage readers to make use of the open dataset we have assembled for this study, which can be accessed by visiting the website of SPARC Stratospheric Network for the Assessment of Predictability (www.sparcsnap.org).

Acknowledgments. The Stratospheric Network for the Assessment of Predictability (SNAP) is supported by the Natural Environment Research Council (NERC) (Grant H5147600) and partially supported by the SPARC.

\section{APPENDIX}

\section{Vortex Structure}

The calculations of the vortex structure (i.e., area, ellipticity, orientation, etc.) corresponding to the equivalent ellipse are based on the PV moments of the 
vortex; more details are given in Melander et al. (1986) and Waugh (1997). We calculate the $(k+m)$ order ( $k$ and $m$ are positive integers) PV moment of the vortex using the PV field via

$$
M=\int p v\left(x^{k}\right)\left(y^{m}\right) d x d y,
$$

where $x$ and $y$ are the coordinate of a PV element with an area element of $d x d y$. For moment calculations, we use modified PV. The modified PV field $q_{m}$ is obtained by replacing the PV value at a grid point with the mean PV from $45^{\circ} \mathrm{N}$ to the North Pole if the PV value of the grid point is less than the mean PV (Matthewman et al. 2009). The mean PV between $45^{\circ} \mathrm{N}$ and the North Pole may be defined as the background PV $q_{b}$. Now we describe the calculations of various diagnostics, using data in the latitude longitude grid. The vortex moment is calculated using Cartesian coordinates. The spherical coordinates of the latitude $\phi$ and the longitude $\lambda$ are transformed to Cartesian coordinates as $X=R \cos \lambda$ and $Y=R \sin \lambda$, where $R=\cos \phi /(1+\sin \phi)$ defines the radius of a latitude circle with the radii one and zero for the equatorial and polar circles, respectively. Using the above transformation equation, we first calculated the Cartesian coordinate of all four corners of each grid box (say $x_{i}$ and $y_{i}$, where $i=1,2,3$, and 4). The area of each grid box bounded by these points $\left(x_{i}, y_{i}\right)$ is given by a simple geometrical formula:

$$
\begin{aligned}
A= & 0.5\left[\operatorname { a b s } \left(x_{1} y_{2}+x_{2} y_{3}+x_{3} y_{4}+x_{4} y_{1}-x_{2} y_{1}\right.\right. \\
& \left.\left.-x_{3} y_{2}-x_{4} y_{3}-x_{1} y_{4}\right)\right] .
\end{aligned}
$$

We define the vortex moments relative to the pole as absolute vortex moments, which are calculated as

$$
M_{j k}=\sum_{i=1}^{n}\left[\left(q_{m}-q_{b}\right)\left(x_{i}^{j}\right)\left(y_{i}^{k}\right) A\right]
$$

In Eq. (A3), the summation is taken over all grid boxes from the equator to the North Pole (say total $n$ grid boxes), $x_{i}$ and $y_{i}$ are the coordinates of the center of the $i$ th grid box, and $q_{m}$ is the modified PV of the grid box. Note that the background PV is constant for each grid box. The zero- and first-order absolute moments give the coordinate of the vortex centroid as

$$
\left(x_{0}, y_{0}\right)=\left(M_{10} / M_{00}, M_{01} / M_{00}\right) .
$$

The coordinate of vortex centroid and absolute vortex moments are then used to calculate the vortex moments relative to the centroid and we term it as the relative vortex moment $J$. The three relative vortex moments required in the calculations are as follows:
$J_{11}=M_{11}-x_{0} M_{01}, \quad J_{20}=M_{20}-x_{0} M_{10}, \quad$ and

$J_{02}=M_{02}-y_{0} M_{01}$.

Once we have all vortex moments, the various elliptical properties are then obtained as

vortex orientation:

$$
\Psi=0.5 \operatorname{atan} 2\left[2 J_{11},\left(J_{20}-J_{02}\right)\right],
$$

equivalent ellipse area:

$$
A_{v}=M_{00} / q_{b}, \quad \text { and }
$$

aspect ratio:

$$
r=\operatorname{sqrt}\left\{\operatorname{abs}\left[\left(r_{1}+r_{2}\right) /\left(r_{1}-r_{2}\right)\right]\right\},
$$

where $r_{1}=J_{20}+J_{02}$ and $r_{2}=\operatorname{sqrt}\left[4 J_{11}\left(J_{11}\right)+\left(J_{20}-J_{02}\right)\right.$ $\left.\left(J_{20}-J_{02}\right)\right]$.

To draw an equivalent ellipse, the aspect ratio, the orientation, and the vortex area are used to calculate the coordinates of the circumference of the ellipse, and are then converted to the spherical coordinates. The aspect ratio $(r=a / b)$ and vortex area $\left(A_{v}=\pi a b\right)$ are used to calculate the major radius $a$ and minor radius $b$ of the equivalent ellipse.

Letting th be an array of numbers from 0 to 360 , the circumference coordinates is given by

$$
\begin{aligned}
x_{\mathrm{pts}}= & x_{0}+a \cos \left(\operatorname{th} \frac{\pi}{180}\right) \cos \left(\Psi \frac{\pi}{180}\right) \\
& -b \sin \left(\operatorname{th} \frac{\pi}{180}\right) \sin \left(\Psi \frac{\pi}{180}\right) \text { and } \\
y_{\mathrm{pts}}= & y_{0}+a \cos \left(\operatorname{th} \frac{\pi}{180}\right) \sin \left(\Psi \frac{\pi}{180}\right) \\
& +b \sin \left(\text { th } \frac{\pi}{180}\right) \cos \left(\Psi \frac{\pi}{180}\right) .
\end{aligned}
$$

Note that to draw the ellipse and centroid on the map, the $x$ and $y$ coordinates need to be converted back to the spherical coordinates $\phi$ and $\lambda$ using the same parametric equations: $X=R \cos \lambda$ and $Y=R \sin \lambda$, where $R=\cos \phi /(1+\sin \phi)$.

\section{REFERENCES}

Allen, D. R., L. Coy, S. D. Eckermann, J. P. McCormack, G. L. Manney, T. F. Hogan, and Y. J. Kim, 2006: NOGAPS-ALPHA simulations of the 2002 Southern Hemisphere stratospheric major warming. Mon. Wea. Rev., 134, 498-518, doi:10.1175/ MWR3086.1.

Andrews, D. G., and M. E. McIntyre, 1976: Planetary waves in horizontal and vertical shear: The generalized Eliassen-Palm relation and the mean zonal acceleration. J. Atmos. Sci., 33, 2031-2048, doi:10.1175/1520-0469(1976)033<2031:PWIHAV >2.0.CO;2.

, and - 1978: An exact theory of non-linear waves on a Lagrangian-mean flow. J. Fluid Mech., 89, 609-646, doi:10.1017/ S0022112078002773. 
—, J. R. Holton, and C. B. Leovy, 1987: Middle Atmosphere Dynamics. Academic Press 489 pp.

Arakawa, A., and V. R. Lamb, 1977: Computational design of the basic dynamical processes of the UCLA general circulation model. Methods Comput. Phys.:Adv. Res. Appl., 17, 173-265, doi:10.1016/B978-0-12-460817-7.50009-4.

Baldwin, M. P., and T. J. Dunkerton, 1999: Propagation of the Arctic Oscillation from the stratosphere to the troposphere. J. Geophys. Res., 104, 30 937-30 946, doi:10.1029/ 1999JD900445.

— , and _ 2001: Stratospheric harbingers of anomalous weather regimes. Science, 294, 581-584, doi:10.1126/science.1063315.

Balmaseda, M. A., K. Mogensen, and A. T. Weaver, 2013: Evaluation of the ECMWF ocean reanalysis system ORAS4. Quart. J. Roy. Meteor. Soc., 139, 1132-1161, doi:10.1002/qj.2063.

Berner, J., G. J. Shutts, M. Leutbecher, and T. N. Palmer, 2009: A spectral stochastic kinetic energy backscatter scheme and its impact on flow-dependent predictability in the ECMWF ensemble prediction system. J. Atmos. Sci., 66, 603-626, doi:10.1175/2008JAS2677.1.

Boville, B. A., and D. P. Baumhefner, 1990: Simulated forecast error and climate drift resulting from the omission of the upper stratosphere in numerical models. Mon. Wea. Rev., 118, 15171530, doi:10.1175/1520-0493(1990)118<1517:SFEACD>2.0.CO;2.

Bowler, N. E., A. Arribas, K. R. Mylne, K. B. Robertson, and S. E. Beare, 2008: The MOGREPS short-range ensemble prediction system. Quart. J. Roy. Meteor. Soc., 134, 703-722, doi:10.1002/qj.234.

Charlton, A. J., and L. M. Polvani, 2007: A new look at stratospheric sudden warmings. Part I: Climatology and modeling benchmarks. J. Climate, 20, 449-469, doi:10.1175/JCLI3996.1.

_ A. O'Neil, W. A. Lahoz, and A. C. Massacand, 2004: Sensitivity of tropospheric forecasts to stratospheric initial conditions. Quart. J. Roy. Meteor. Soc., 130,1771-1792, doi:10.1256/qj.03.167.

Charney, J. G., and N. A. Phillips, 1953: Numerical integration of the quasi-geostrophic equations for barotropic and simple baroclinic flows. J. Meteor., 10, 71-99, doi:10.1175/1520-0469(1953)010<0071: NIOTQG $>2.0 . \mathrm{CO} ; 2$.

Chua, B., L. Xu, T. Rosmond, and E. Zaron, 2009: Preconditioning representer-based variational data assimilation systems: Application to NAVDAS-AR. Data Assimilation for Atmospheric, Oceanic and Hydrologic Applications, S. K. Park and L. Xu, Eds., Springer-Verlag, 307-319.

Davies, T., M. J. P. Cullen, A. J. Malcolm, M. H. Mawson, A. Staniforth, A. A. White, and N. Wood, 2005: A new dynamical core for the Met Office's global and regional modelling of the atmosphere. Quart. J. Roy. Meteor. Soc., 131, 1759-1782, doi:10.1256/qj.04.101.

Dörnbrack, A., M. C. Pitts, L. R. Poole, Y. J. Orsolini, K. Nishii, and H. Nakamura, 2012: The 2009-2010 Arctic stratospheric winter-General evolution, mountain waves and predictability of an operational weather forecast model. Atmos. Chem. Phys., 12, 3659-3675, doi:10.5194/acp-12-3659-2012.

Edwards, J., and A. Slingo, 1996: Studies with a flexible new radiation code. I: Choosing a configuration for a large-scale model. Quart. J. Roy. Meteor. Soc., 122, 689-719, doi:10.1002/ qj. 49712253107.

Emanuel, K. A., 1991: A scheme for representing cumulus convection in large-scale models. J. Atmos. Sci., 48, 2313-2329, doi:10.1175/1520-0469(1991)048<2313:ASFRCC >2.0.CO;2. , and M. Zivkovic-Rothman, 1999: Development and evaluation of a convection scheme for use in climate models. J. Atmos. Sci., 56, 1766-1782, doi:10.1175/1520-0469(1999)056<1766: DAEOAC $>2.0 . \mathrm{CO} ; 2$.
Essery, R., M. Best, and P. Cox, 2001: MOSES 2.2 technical documentation. Hadley Centre Tech. Note 30, Met Office, Exeter, United Kingdom.

Fraser, J., 2012: APS1 upgrade of the ACCESS-G Numerical Weather Prediction system. NMOC Operations Bull. 93, Bureau of Meteorology, 29 pp. [Available online at http://www.bom.gov.au/ australia/charts/bulletins/apob93.pdf.]

Gregory, D., and P. R. Rowntree, 1990: A mass flux convection scheme with representation of cloud ensemble characteristics and stability-dependent closure. Mon. Wea. Rev., 118, 1483-1506, doi:10.1175/1520-0493(1990)118<1483:AMFCSW>2.0.CO;2.

Harshvardhan, R. Davies, D. A. Randall, and T. G. Corsetti, 1987: A fast radiation parameterization for atmospheric circulation models. J. Geophys. Res., 92, 1009-1016, doi:10.1029/ JD092iD01p01009.

Hirooka, T., T. Ichimaru, and H. Mukougawa, 2007: Predictability of stratospheric sudden warmings as inferred from ensemble forecast data: Intercomparison of 2001/02 and 2004/04 winters. J. Meteor. Soc. Japan, 85, 919-925, doi:10.2151/jmsj.85.919.

Hitchcock, P., and T. G. Shepherd, 2013: Zonal-mean dynamics of extended recoveries from stratospheric sudden warmings. J. Atmos. Sci., 70, 688-707, doi:10.1175/JAS-D-12-0111.1.

Iwasaki, T., S. Yamada, and K. Tada, 1989: A parameterization scheme of orographic gravity wave drag with the different vertical partitioning, Part 1: Impact on medium range forecast. J. Meteor. Soc. Japan, 67, 11-41.

Japan Meteorological Agency, 2007: Outline of the operational numerical weather prediction at the Japan Meteorological Agency (Appendix to WMO numerical weather prediction progress report). Japan Meteorological Agency, 194 pp. [Available online at http://www.jma.go.jp/jma/jma-eng/ jma-center/nwp/outline-nwp/index.htm.]

Jung, T., and J. Barkmeijer, 2006: Sensitivity of the tropospheric circulation to changes in the strength of the stratospheric polar vortex. Mon. Wea. Rev., 134, 2191-2207, doi:10.1175/ MWR3178.1.

—, and M. Leutbecher, 2007: Performance of the ECMWF forecasting system in the Arctic during winter. Quart. J. Roy. Meteor. Soc., 133, 1327-1340, doi:10.1002/qj.99.

Kuroda, Y., 2010: High initial-time sensitivity of medium-range forecasting observed for a stratospheric sudden warming. Geophys. Res. Lett., 37, L16804, doi:10.1029/2010GL044119.

Leblanc, T., O. P. Tripathi, I. S. McDermid, L. Froidevaux, N. J. Livesey, W. G. Read, and J. W. Waters, 2006: Simultaneous lidar and EOS MLS measurements, and modelling, of a rare polar ozone filament event over Mauna Loa Observatory, Hawaii. Geophys. Res. Lett., 33, L16801, doi:10.1029/ 2006 GL026257.

Leovy, C. B., C.-R. Sun, M. H. Hitchman, E. E. Remsberg, J. M. Russell, L. L. Gordley, J. C. Gille, and L. V. Lyjak, 1985: Transport of ozone in the middle stratosphere: Evidence for planetary wave breaking. J. Atmos. Sci., 42, 230-244, doi:10.1175/1520-0469(1985)042<0230:TOOITM>2.0.CO;2.

Limpasuvan, V., D. Thompson, and D. Hartmann, 2004: The life cycle of the Northern Hemisphere sudden stratospheric warmings. J. Climate, 17, 2584-2596, doi:10.1175/1520-0442(2004)017<2584: TLCOTN $>2.0$. CO; 2 .

Lock, A. P., A. R. Brown, M. R. Bush, G. M. Martin, and R. N. B. Smith, 2000: A new boundary layer mixing scheme. Part I: Scheme description and single-column model. Mon. Wea. Rev., 128, 3187-3199, doi:10.1175/1520-0493(2000)128<3187: ANBLMS $>2.0 . \mathrm{CO} ; 2$. 
Lott, F., and M. J. Miller, 1997: A new subgrid-scale orographic drag parameterization: Its formulation and testing. Quart. J. Roy. Meteor. Soc., 123, 101-127, doi:10.1002/qj.49712353704.

Louis, J. F., 1979: A parametric model of vertical eddy fluxes in the atmosphere. Bound.-Layer Meteor., 17, 187-202, doi:10.1007/ BF00117978.

— M. Tiedtke, and J. F. Geleyn, 1982: A short history of the operational PBL-parameterization at ECMWF. Proc. ECMWF Workshop on Boundary Layer Parameterization, Reading, United Kingdom, ECMWF, 59-79.

Manney, G. L., and Coauthors, 2008: The evolution of the stratopause during the 2006 major warming: Satellite data and assimilated meteorological analyses. J. Geophys. Res., 113, D11115, doi:10.1029/2007JD009097.

Marshall, A. G., and A. A. Scaife, 2010: Improved predictability of stratospheric sudden warming events in an atmospheric general circulation model with enhanced stratospheric resolution. J. Geophys. Res., 115, D16114, doi:10.1029/2009JD012643.

Matthewman, N. J., and J. G. Esler, 2011: Stratospheric sudden warmings as self-tuning resonances. Part I: Vortex splitting events. J. Atmos. Sci., 68, 2481-2504, doi:10.1175/ JAS-D-11-07.1.

$\longrightarrow,-$ A. J. Charlton-Perez, and L. M. Polvani, 2009: A new look at stratospheric sudden warmings. Part III: Polar vortex evolution and vertical structure. J. Climate, 22, 1566-1585, doi:10.1175/2008JCLI2365.1.

McIntyre, M. E., and T. N. Palmer, 1983: Breaking planetary waves in the stratosphere. Nature, 305, 593-600, doi:10.1038/ 305593a0

— Terr. Phys., 46, 825-849, doi:10.1016/0021-9169(84)90063-1.

McLay, J. G., C. H. Bishop, and C. A. Reynolds, 2010: A local formulation of the ensemble transform (ET) analysis perturbation scheme. Wea. Forecasting, 25, 985-993, doi:10.1175/ 2010WAF2222359.1.

Mechoso, C. R., K. Yamazaki, A. Kitoh, and A. Arakawa, 1985: Numerical forecasts of stratospheric warming events during the winter of 1979. Mon. Wea. Rev., 113, 1015-1029, doi:10.1175/1520-0493(1985)113<1015:NFOSWE>2.0.CO;2.

—, M. J. Suarez, K. Yamazaki, A. Kitoh, and A. Arakawa, 1986: Numerical forecasts of tropospheric and stratospheric events during the winter of 1979: Sensitivity to the model's horizontal resolution and vertical extent. Advances in Geophysics, Vol. 29, Academic Press, 375-413.

Melander, M. V., N. J. Zabusky, and A. S. Styczek, 1986: A moment model for vortex interactions of the two dimensional Euler equations. Part I. Computational validation of a Hamiltonian elliptical representation. J. Fluid Mech., 167, 95-115, doi:10.1017/S0022112086002744.

Mitchell, D. M., A. J. Charlton-Perez, and L. J. Gray, 2011: Characterizing the variability and extremes of the stratospheric polar vortices using 2D moment analysis. J. Atmos. Sci., 68, 1194-1213, doi:10.1175/2010JAS3555.1.

_ L. L. J. Gray, J. Anstey, M. P. Baldwin, and A. Charlton-Perez, 2013: The influence of stratospheric vortex displacements and splits on surface climate. J. Climate, 26, 2668-2682, doi:10.1175/JCLI-D-12-00030.1.

Mizuta, R., and Coauthors, 2012: Climate simulations using MRIAGCM3.2 with 20-km grid. J. Meteor. Soc. Japan, 90A, 233 258, doi:10.2151/jmsj.2012-A12.

Molteni, F., and Coauthors, 2011: The new ECMWF seasonal forecast system (System 4). ECMWF Tech. Memo. 656, ECMWF, Reading, United Kingdom, 49 pp. [Available online at http://www.ecmwf.int/sites/default/files/elibrary/2011/ 11209-new-ecmwf-seasonal-forecast-system-system-4.pdf.]

Mukougawa, H., and T. Hirooka, 2004: Predictability of stratospheric sudden warming: A case study for 1998/99 winter. Mon. Wea. Rev., 132, 1764-1776, doi:10.1175/1520-0493(2004)132<1764: POSSWA $>2.0 . \mathrm{CO} ; 2$.

- , H. Sakai, and T. Hirooka, 2005: High sensitivity to the initial condition for the prediction of stratospheric sudden warming. Geophys. Res. Lett., 32, L17806, doi:10.1029/2005GL022909.

Roff, G., D. W. J. Thompson, and H. Hendon, 2011: Does increasing model stratospheric resolution improve extendedrange forecast skill? Geophys. Res. Lett., 38, L05809, doi:10.1029/2010GL046515.

Rosmond, T., and L. Xu, 2006: Development of NAVDAS-AR: Non-linear formulation and outer loop tests. Tellus, $\mathbf{5 8 A}, 45-$ 58, doi:10.1111/j.1600-0870.2006.00148.x.

Scherhag, R., 1952: Die explosionsartigen Stratosphärenerwämungen des Spätwinters 1951. 52. Ber. Deutsch. Wetterdienst, 6, 51-61.

Scinocca, J. F., 2003: An accurate spectral nonorographic gravity wave drag parameterization for general circulation models. J. Atmos. Sci., 60, 667-682, doi:10.1175/1520-0469(2003)060<0667: AASNGW $>2.0 . \mathrm{CO} ; 2$.

Shaw, T. A., J. Perlwitz, and N. Harnik, 2010: Downward wave coupling between the stratosphere and troposphere: The importance of meridional wave guiding and comparison with zonal-mean coupling. J. Climate, 23, 6365-6381, doi:10.1175/ 2010JCLI3804.1.

Sigmond, M., J. F. Scinocca, V. V. Kharin, and T. G. Shepherd, 2013: Enhanced seasonal forecast skill following stratospheric sudden warmings. Nat. Geosci., 6, 98-102, doi:10.1038/ngeo1698.

Simmons, A., M. Hortal, G. Kelly, A. McNally, A. Untch, and S. Uppala, 2003: Analyses and forecasts of stratospheric winter polar vortex break-up: September 2002 in the Southern Hemisphere and related events from ECMWF operations and ERA-40. ERA-40 Report Series, Rep. 5, ECMWF, 28 pp. [Available online at http://www.ecmwf.int/sites/default/files/ elibrary/2003/12239-analyses-and-forecasts-stratospheric-winterpolar-vortex-break-september-2002-southern.pdf.]

,,,,----- , and,- 2005 : ECMWF analyses and forecasts of stratospheric winter polar vortex breakup September 2002 in the Southern Hemisphere and related events. J. Atmos. Sci., 62, 668-689, doi:10.1175/JAS-3322.1.

Slingo, J. M., 1987: The development and verification of a cloud prediction scheme for the ECMWF model. Quart. J. Roy. Meteor. Soc., 113, 899-927, doi:10.1002/qj.49711347710.

Stan, C., and D. M. Straus, 2009: Stratospheric predictability and sudden stratospheric warming events. J. Geophys. Res., 114, D12103, doi:10.1029/2008JD011277.

Teixeira, J., 2001: Cloud fraction and relative humidity in a prognostic cloud fraction scheme. Mon. Wea. Rev., 129, 1750-1753, doi:10.1175/1520-0493(2001)129<1750:CFARHI > 2.0.CO;2.

— mospheric model: Simple cloud cover parameterizations. J. Climate, 15, 1261-1276, doi:10.1175/1520-0442(2002)015<1261: BLCIAG $>2.0 . C O ; 2$.

Thompson, D. W. J., M. P. Baldwin, and J. M. Wallace, 2002: Stratospheric connection to Northern Hemisphere wintertime weather: Implications for prediction. J. Climate, 15, 1421-1428, doi:10.1175/1520-0442(2002)015<1421:SCTNHW>2.0.CO;2.

Tiedtke, M., 1984: The sensitivity of the time-scale flow to cumulus convection in the ECMWF model. Proc. Workshop on LargeScale Numerical Models, Reading, United Kingdom, ECMWF, 297-316. 
_ 1993: Representation of clouds in large-scale models. Mon. Wea. Rev., 121, 3040-3061, doi:10.1175/1520-0493(1993)121<3040: ROCILS $>2.0 . C O ; 2$.

Tripathi, O. P., T. Leblanc, I. S. McDermid, F. Lefèvre, M. Marchand, and A. Hauchecorne, 2006: Forecast, measurement, and modeling of an unprecedented polar ozone filament event over Mauna Loa Observatory, Hawaii. J. Geophys. Res., 111, D20308, doi:10.1029/2006JD007177.

_ - and Coauthors, 2015: The predictability of the extratropical stratosphere on monthly time-scales and its impact on the skill of tropospheric forecasts. Quart. J. Roy. Meteor. Soc., 141, 987-1003, doi:10.1002/qj.2432.

Walters, D. N., and Coauthors, 2014: The Met Office Unified Model Global Atmosphere 4.0 and JULES Global Land 4.0 configurations. Geosci. Model Dev., 7, 361-386, doi:10.5194/gmd-7-361-2014.

Warner, C. D., and M. E. McIntyre, 2001: An ultrasimple spectral parameterization for nonorographic gravity waves. J. Atmos. Sci., 58, 1837-1857, doi:10.1175/1520-0469(2001)058<1837: AUSPFN $>2.0 . \mathrm{CO} ; 2$.

Waugh, D. W., 1997: Elliptical diagnostics of stratospheric polar vortices. Quart. J. Roy. Meteor. Soc., 123, 1725-1748, doi:10.1002/qj.49712354213.

- and W. J. Randel, 1999: Climatology of Arctic and Antarctic polar vortices using elliptical diagnostics. J. Atmos. Sci.,
56, 1594-1613, doi:10.1175/1520-0469(1999)056<1594: COAAAP $>2.0 . \mathrm{CO} ; 2$.

Webster, S., A. R. Brown, D. R. Cameron, and C. P. Jones, 2003: Improvements to the representation of orography in the Met Office Unified Model. Quart. J. Roy. Meteor. Soc., 129, 19892010, doi:10.1256/qj.02.133.

Wilson, D. R., and S. P. Ballard, 1999: A microphysically based precipitation scheme for the UK Meteorological Office Unified Model. Quart. J. Roy. Meteor. Soc., 125, 1607-1636, doi:10.1002/qj.49712555707.

—, A. C. Bushell, A. M. Kerr-Munslow, J. D. Price, and C. J. Morcrette, 2008: PC2: A prognostic cloud fraction and condensation scheme. I: Scheme description. Quart. J. Roy. Meteor. Soc., 134, 2093-2107, doi:10.1002/qj.333.

Yabu, S., R. Mizuta, H. Yoshimura, Y. Kuroda, and H. Mukougawa, 2014: Meteorological Research Institute Ensemble Prediction System (MRI-EPS) for climate researchOutline and its applications. Tech. Rep. 71, Meteorological Research Institute.

Yoshimura, H., R. Mizuta, and H. Murakami, 2015: A spectral cumulus parameterization scheme interpolating between two convective updrafts with semi-Lagrangian calculation of transport by compensatory subsidence. Mon. Wea. Rev., 143, 597-621, doi:10.1175/MWR-D-14-00068.1. 